\title{
Chapter 23 \\ Zoonoses Animal and Human Diseases Endo and Ectoparasites Mainly Mammal I
}

\subsection{Introduction}

The definition of a zoonosis is that it must affect man but the term is used often outside of medical terminology of animal diseases where man is not involved. Zoonoses are diseases naturally transmitted between animals and man and comprise in total about $80 \%$ of all described human infections. Attempts have been made to define different classes of zoonoses according to the man-animal relationship but generally this does not seem to have been accepted. Elton in 1927 stressed the field of wild animal pathology was still virtually untouched, and in 1968 McDiarmid reiterated the view that it remained one of the most neglected aspects of animal ecology. There is now an extensive literature but it is rarely incorporated into ecological texts although disease is often the driving force in population dynamics. The primary driver of infectious disease dynamics is transmission between individuals, yet in most important respects remarkably little is known about the subject (Craft et al. 2008, Haydon 2008). Occasionally, under high population densities, an organism may infect a host outside of its normal range with highly pathogenic effect in its adventitious host.

Human infectious diseases are not distributed at random, contagious diseases are everywhere but zoonotic pathogens are more locally concentrated in the tropics where humans suffer a greater diversity of pathogens. Given the vast number of parasites with which humans have almost daily contact, it is clear that only a small number is able to infect hosts other than those which they actually live upon, thus accidental diseases are rare. Nearly all hosts are resistant to nearly all parasites (Ebert and Bull 2007). Altogether man is subject to more than 1,400 human pathogen species of which over 800 (about $60 \%$ of all known species) are shared by man with other vertebrates, mostly other mammals, and relatively few occur as human pathogens only (Woolhouse and Antia 2007). Some 13\% are considered as emerging or re-emerging. Within any one species there may be a number of variants of different virulence, different abilities to infect, or with different receptor specificities. Of all the pathogenic species, 208 are viruses or prions, ${ }^{1} 37 \%$ of 
which $(\mathrm{n}=77)$ are emerging or re-emerging diseases. Bacteria account for 538 with $10 \%(\mathrm{n}=54)$ emerging or re-emerging; protozoa 57 with $25 \%(\mathrm{n}=14)$ emerging or re-emerging, and helminths 237 with $3 \%(\mathrm{n}=10)$ emerging or reemerging. Ungulates are the most important overall hosts supporting 250 species of human pathogen, and are the most important source of emerging pathogens with more than 50 species, of which over $40 \%$ have the broadest host ranges. The emerging pathogens seem to be mainly viruses (Woolhouse and Gowtage-Sequeria 2005).

In some cases emerging pathogens and the increase of known infections may be due to a loss of cross-immunity, the isolation of man from repeated infection by non-pathogenic species. Experiments have shown exposure to schistosomes from domestic stock and wild animals reduces severity of infection by the human parasites Schistosoma mansoni and S. haematobium, and in areas where filariasis or onchocerciasis is endemic man is exposed to repeated infections with filarias of animals which may modify the disease in man (Nelson 1974). Multiple infections of arboviruses in wild animals, a conceptual grouping in which the vector is a blood-sucking arthropod, usually a mosquito or a tick, may provide cross-immunity to the more pathogenic ones, but man, by his change in lifestyle and hygiene, increasingly isolates himself from all infection, thus leaving him without naturally acquired immunity.

Transfers to man as an adventitious host of animal diseases through chance contacts must have taken place repeatedly throughout mankind's history and be expected to increase as population numbers increase. Set against this may be the declining numbers of wild animals and improved hygiene. But with the development of animal husbandry new opportunities for parasitism arose primitively. Cattle, horses, pigs, sheep, and goats, but particularly sheep because of their close association with primitive husbandmen who slept at night with their animals, may have been chronic bearers of infections because they were gregarious and, apart from pigs and goats, pastured on the grasslands of Eurasia in vast herds providing the precise conditions required to allow bacterial and viral infections to become enzootic, the hosts acquiring an immunity but the diseases often being deadly when transferred to man. The process still continues, as for example with swine flu'. When man develops a tolerance to such an adventitious animal disease it becomes endemic in the human population.

A huge array of endo and ectoparasites parasitizes the African fauna, a scarcely known bewildering multitude with often fascinating and complex life histories. An example is the blind and flightless viviparous earwig species Hemimerus, the only parasitic species of earwig in the Ethiopian Region, seven species of which have become ectoparasites of the giant rats Cricetomys gambianus and C. eminii, spending their entire life history on the rat living on scurf and fungi and therefore possibly commensals rather than parasites. These are in turn are parasitized by two species of mite Andréacarus petersi and A. zumpti. Surprisingly, ectoparasites tend to be composed of many species endemic to the Ethiopian Region while the opposite is true of endoparasites. Surprisingly because ectoparasites, in the form of lice, fleas, mites, and ticks, are more readily carried by migratory birds, predisposing towards 
a wider distribution. But for example, the only elephant arthropod parasite not host specific to elephants, excluding biting flies and ticks, is the calliphorid fly Chrysomia bezziana, larvae of which cause an obligate wound myiasis in a wide range of mammals including man.

The popular belief that wild animals are resistant to many diseases affecting domestic stock is based upon the false assumption that disease does not exist because affected animals are seldom seen, sick animals tend to hide themselves and are taken by predators, and their removal by predators or their death in isolated areas obscures the true incidence of disease. As long ago as 1857 Livingstone was aware of the truth of the matter,

Inquiries among the Bushmen and Bakalahari, who are intimately acquainted with the habits of the game, lead to the belief that many diseases prevail among wild animals. I have seen the kokong or gnu, káma or hartebeest, the tsessébe, kukama, and the giraffe, so mangy as to be uneatable even by the natives. Reference has already been made to the peripneumonia which cuts off horses, tolos or koodoos. Great numbers also of zebras are found dead with masses of foam at the nostrils, exactly as occurs in the common "horsesickness". The production of the malignant carbuncle... is another proof of the disease of the tame and wild being identical. I once found a buffalo blind from ophthalmia... The rhinoceros often has worms on the conjunction of his eyes...

All the wild animals are subject to intestinal worms besides. I have observed bunches of a tape-like thread and short worms of enlarged sizes in the rhinoceros. The zebras and elephants are seldom without them, a thread-worm may often be seen under the peritoneum of these animals. Short red larvae, which convey a stinging sensation to the hand, are seen clustering around the orifice of the windpipe (trachea) of this animal at the back of the throat; others are seen in the frontal sinuses of antelopes; and curious flat leech-like worms with black eyes are found in the stomachs of leches [lechwes].

Thomas and Neitz (1933) observed that disease affecting wild animals "with serious loss to themselves, to stock or man or all three, are by no means rare or unimportant.

There is ample proof wild animals are susceptible to many arthropod-borne diseases. At least seven viruses are known to have a natural transmission cycle involving argasid ticks (Plowright et al. 1970). Protozoan diseases transmitted by ticks such as babesiosis or redwater fever, theileriosis or East Coast Fever ECF, Corridor disease; and the rickettsial anaplasmosis or gall-sickness of cattle, caused by unicellular parasites which invade blood cells, particularly erythrocytes; have been implicated in mortality. Although non-clinical, anaplasmosis has been recorded in experimental duiker Sylvicapra grimmia, blesbok Damaliscus dorcas phillipsi, and black wildebeest Connochaetes gnou. It has been suspected as the cause of death in a giraffe and a captive sable antelope died of babesiosis. Fatal theileriosis, formerly attributed to cytauxzoonosis, has been described in giraffe, eland, and duiker, and clinical and histopathological evidence found in a young buffalo (Carmichael and Hobday 1975).

Fosbrooke (1963) described how lions in Ngorongoro Crater were affected in 1962 by an outbreak of the blood-sucking stable fly allegedly Stomoxys calcitrans. Although no lion deaths were observed the population dropped from 60 to 15 by death or emigration with lions observed to have many raw patches on their skin. In Nairobi NP a mixture of eight species (S. varipes, S. inornatus, S. taeniatus, S. niger niger, S. transvittatus, S. taeniatus $f$. brunnipes, $S$. pallidus, S. calcitrans) had 
bushbuck as the preferred host by far, followed by black rhinoceros and warthog. Common species such as giraffe, buffalo, and impala, were not detected in blood meals (Mihok and Clausen 1996), contrary to QENP where buffalo was found to be the preferred host after bushbuck (Kangwagye 1977). High numbers of S. varipes were found on a moribund bushbuck in Kenya's Aberdare Mountains during an apparent die-off of bushbuck (Mihok and Clausen 1996). In April-May 1997 an outbreak of $S$. omega was reported over more than $2,000 \mathrm{~km}^{2}$ in northern Congo Republic and adjacent areas, apparently leading to mortality among low density forest species, namely bongo (17 deaths recorded), yellow backed duiker (four possible deaths recorded), sitatunga, and forest buffalo, preceded as in some other areas by an outbreak of the large non-biting fly Fainia elongata bezzi. Stomoxys were seen to swarm over the animals causing the bongo to keep moving during the heat of the day until exhausted. Some were recorded as moving away from favoured areas returning later. Examination of the cadavers of four bongo and one buffalo revealed the animals may have been weakened by helminth Elaeophora sagitta infection and possibly low nutrition, forage being poor at the peak of the outbreak, but had been exsanguinated and driven to exhaustion by the Stomoxys (Huchzermeyer et al. 2001). The outbreak followed a prolonged severe dry season succeeded by exceptionally heavy rains (Elkan et al. 2009). Similar climatic conditions were reported for the Ngorongoro Crater outbreak. According to local report Stomoxys outbreaks occur annually in April-May in northern DR Congo but numbers are lower and the duration shorter, not noticeably affecting wild animals.

Usually studies of the health of wild animals have been limited to descriptions of ecto and endo parasites and there are few comparative studies. Illustrative of what can be found, of five duiker species, blue duiker Cephalophus monticola $(\mathrm{n}=23)$, black-fronted duiker $C$. nigrifrons $(\mathrm{n}=5)$, white-bellied duiker $C$. leucogaster ( $\mathrm{n}=11)$, Weyn's duiker $C$. weynsi $(\mathrm{n}=12)$, and black-backed or bay duiker C. dorsalis $(\mathrm{n}=10)$, studied by Karesh et al. (1995) in the Epulu forest, DR Congo, all were positive for bluetongue virus BT, epizootic haemorrhagic disease EHD, infectious bovine rhinotracheitis IBR, and Leptospira interrogans. All were negative for bovine viral diarrhoea, brucellosis, FMD, and rinderpest. A total of $70 \%$ was positive for EHD which has been rarely reported from animals in Africa and is probably in the bluetongue group or a closely related virus. A total of $90 \%$ was positive for BT. Coetzer and Tutin (2004) provide details of many diseasecausing endoparasites affecting domestic stock. This overview touches upon some of the more common diseases and parasites only, to illustrate their often complex and central roles in the ecology of wild animals.

\subsection{Bacterial Diseases}

From four of the duiker species in the Ituri Forest Karesh et al. (1995) found positive antibody reactions ranging from $17 \%$ to $70 \%$ for five serotypes of the spirochæte bacterium Leptospira interrogans, which is transmitted indirectly 
through water or mud contaminated with infected urine, or from the latter direct. Leptospirosis is the most widespread zoonosis in the world with the brown rat and Mus musculus the known most important reservoirs, although a wide range of other hosts from cattle to shrews, reptiles and amphibians, has been identified worldwide, but rodents particularly so. When contracted by humans most recover but it can be fatal. Few wild animal reservoirs have been found in Africa despite a high prevalence in domestic stock, but it is widespread in African rodents. It may exist in the host without causing pathological damage and none was identified in duikers examined in Benin where almost $52 \%$ of rodents examined, mainly brown rat, were positive for leptospires. In Harare, Zimbabwe, 49 strains of leptospire were isolated, 43 from black rat, two from Mastomys spp., and four from M. musculus (Feresu and Dalu 1996). Isolates have been made from Arvicanthis niloticus in the Nile Delta, A. abyssinicus in DR Congo, and the gerbil T. robusta vicinia in Kenya. One seropositive reaction was obtained from a Mastomys sp. in South Africa, and in Natal positive antibody responses were found in black rhinoceros, bushbuck, nyala, reedbuck, and black wildebeest (Hunter 2004).

\subsubsection{Bubonic Plague}

\subsubsection{Non-human Mortality Other than Rats}

Several historical writers have referred to bubonic plague, inferred as caused by the bacterium Yersinia pestis, affecting a variety of animals, fish, birds, and mammals. In many cases there seem to be confusions with anthrax or rinderpest. John of Ephesus reported the plague affecting animals, "We also noted that this powerful plague had its effect even on animals-not only on the domestic ones, but also on those of the steppe, including even the reptiles of the earth. It was possible to see cattle, dogs, other animals, and even mice, whose groins were swollen and were cast away and dead. Likewise the animals of the steppe were found struck, cast away and dead, all by this same verdict" (Harrak 1999). Y. pestis is pathogenic to most mammals in the laboratory.

The Chronicon Jacobi Edesseni (Chabot 1899-1924) and the Chronique de Séert (Sher 1908-1950) record that at sometime between the end of a famine in 546 and the year 552 there was an epizootic among cattle throughout the entire East which lasted for 2 years, the former source stating fields went uncultivated for lack of oxen, the latter, giving a date of 552-553, that people used camels, asses, and beasts of burden, for ploughing. This plague was probably rinderpest. In 763-764 there was an enzootic among horses, mules, and donkeys, attributed to bubonic plague because of the swellings in the neck of the victims, but this latter is characteristic of equine anthrax, "... scarcely one in a hundred of the animals afflicted survived. The disease spread throughout all the nations and kingdoms of the earth" (Harrak 1999). 
When the Black Death spread along the Mediterranean coast in 1348-1349 several Arab sources referred to animals dying. A description of buboes found on the heads of fish by al-Maqrīzī can be explained by warty excrescences simply being noticed because of the talk of buboes, some species of fish developing them as secondary sexual characteristics in the breeding season (although the author has not identified any fish from this region that do so), or in the case of the Egyptian anuma this silvery fish has black spots on the dorsal region. Fish can suffer from many diseases, some of which cause swellings on the body. The description of Ibn Iyās (1453-1468) that "The piercing [i.e. the plague] also occurred to cats, dogs, and savage beasts. One found in the desert the bodies of savage animals with the bubos under their arms. It was the same with horses, camels, asses, and all the beasts in general, including birds, even the ostriches" (Kahle et al. 1960-1963), most likely refers to anthrax, in the case of cattle, rinderpest; or starvation through famine where domestic animals had no herders to attend them, simply being associated with the contemporaneous human mortality. Al-Maqrīzī ( $c 1349)$ likewise described animal deaths, "The falcons of the chase. . overtook the wild geese or other birds; on the prey was always found a bubo [kubbah] about the size of a hazelnut. Numerous dead birds were found in the fields - crows, kites, and many other birds of all kinds. When they were plucked, one found traces of the bubo. Cats died until practically no more were seen. According to the information that arrived constantly from the Ghaur [Jordan Valley], from Baysān, and from other neighbouring villages, lions, wolves, hares, camels, wild asses, wild boars, and other savage beasts all lay dead and on them was the trace of the bubo" (Al-Maqrīzī, 1936-1958). In Bilbais the majority of dromedaries belonging to the sultan and amirs died. As Dols (1977) noted, despite an abundance of rats known to exist at this period in the Middle East, there is no reference to rats dying as would be expected with bubonic plague.

Nicephoras Gregoras wrote in his history of Byzantium that not only was mankind affected in the plague of 1348 but all other animals as well that dwelt with or associated with human beings, "dogs and horses and fowls as well, and even the mice that lived within the walls of their houses" (Bartsocas 1966). Already in 1347 in Padua it was reported that once the disease entered a dwelling even the animals were seized of it, and when Holstein was affected in 1350 it allegedly raged in both man and cattle. At Avignon, dogs, cats, and hens, died. Later writers refer to snakes, moles rabbits, foxes, badgers, and martens, having been seen to die before or during plague epidemics (Simpson 1905). Rocher (1879) reported from Yunnan that animals great and small, such as buffaloes, oxen, sheep, deer, and sometimes court-yard fowls, died of the plague. Dols (1977) stated there were extraordinary accounts of the destruction of animals in a severe outbreak which spread from Syria to Egypt in 1430.

Referring to a plague outbreak at Alexandria in 1834 a correspondent stated it began with dogs, having been very deadly in Smyrna (Izmir) and then in various other islands and in Egypt. From dogs it had passed to cattle, and it had been noted that some cattle sent to the abattoir at Alexandria had died of anthrax. One of these animals was alleged to have a tumour like that of the plague seen in 
man (De Lesseps 1846). In fact, rinderpest was widespread in Europe and Turkey at this time. This would not have affected dogs in which the disease probably was anthrax. Cholet (1846), who witnessed the epidemic in Constantinople in 1834, was certain an epizootic co-existed with the plague, numbers of chickens dying purchased by a ship's captain at Constantinople, while others bought at Odessa did not. Birds also allegedly abandoned the Turkish quarter of Constantinople for the duration of the plague.

In 1871 there was a severe plague outbreak in Hongkong accompanied by a mortality of rats and also pigs and cattle (Simpson 1905).

Twigg (1984) suggested the fourteenth century Black Death in Britain could have been caused by anthrax. In a small epidemic in Nepal in 1967 because both humans and cattle were affected the deaths were attributed to anthrax, until tests showed the cattle were dying from rinderpest and the people of bubonic plague. Such coincidences may arise from climatic conditions like drought encouraging diverse diseases simultaneously.

But in several regions of India in 1897 and 1898 monkeys were seen to fall from the trees and die in the streets, tests showing they were infected with the plague bacillus. In 1899 at Newchang, chickens, ducks, geese, pigs, dogs, deer, and cattle, were observed dying in unusually large numbers when many human deaths were taking place from an outbreak. Clinical tests conducted at Bombay found the following animals died after injection or feeding of the bacillus: mongoose, squirrel, guinea-pig, rabbit, jackal, dog, hyena, cat, pig, monkeys, and pigeons. Horse, ox, sheep, goat, cat, dog, pig, hens, and geese were affected but recovered, the reaction probably dependent upon the quantity of bacilli received in the case of large animals and the manner of administration. Health of the animal could also be a factor, thus pigeons and sparrows succumbed when starved first. Dogs, while uninfected by being fed the bacilli, passed virulent bacilli in their excreta. Later tests conducted in 1902 showed that calves, hens, turkeys, geese, pigeons, sheep, and pigs, were all susceptible both by inoculation and feeding, pigs and poultry to a high degree (Simpson 1905), but experiments in Natal failed to produce the disease in fowls, pigs, or cattle. Mice as well as rats are sometimes, but not often, seen to be affected during an epidemic. Mice died in a plague in Formosa and in 1898 at Jedda.

\subsubsection{Brucellosis}

Brucellosis is a worldwide bacterial zoonosis known to be present in hoofed animals since ancient times and changes in bone structure indicative of it have been found in fossilized remains, while its presence in man in ancient Greece is seen by some as attested to by Hippocrates. Its incidence in man in Africa is low to sporadic over most of the continent, especially in the low-rainfall zones of the north, east, and south. Most countries report a low to sporadic incidence with the exceptions of Tanzania and DR Congo with moderate, and Nigeria a high, incidence. The major reservoir appears to be in sheep and goats, and thus its incidence 
in man is highest where contact with small stock is most intimate. The bacteria can survive for up to 6 months in water and in humid organic environments. So far six species are known at least four of which are known to affect man: Brucella melitensis of goats and sheep, Br. abortus of cattle, $\mathrm{Br}$. suis of pigs, reindeer or caribou, and hare, and $\mathrm{Br}$. ovis of sheep; while $\mathrm{Br}$. canis of dogs and $\mathrm{Br}$. neotomae of the desert wood rat Neotoma lepida in America, are little known, the former found in dogs in Madagascar and not on the African continent. Jackals and hyaenas are incidental hosts to both $\mathrm{Br}$. melitensis and $\mathrm{Br}$. abortus. Man is considered a "dead end" for the disease acquiring it almost exclusively from infected domestic animals and hunters from infected wild animals, rarely transmitting it to others. "Infectious abortion" and "malarial continued fevers" were well known among the first settlers in America in 1557.

Brucellosis or Malta fever caused by Br. melitensis was described from Ankole as early as 1906 , with as many as $25 \%$ of people in one village infected in the southwest. In 1909 it was reported by local people that a "new disease" called muhinyo had spread rapidly along the eastern shore of Lake Edward being most severe at Katwe. Entering Uganda from the north it expanded along the great lakes to the south and south-east but there was nothing to show how it originated. It was contracted by drinking infected goat's milk (Bruce 1910).

Animal brucellosis, or contagious abortion, caused by $\mathrm{Br}$. abortus, and as its name implies causing abortion, is the most widely spread in the tropics and subtropics believed to occur throughout Africa, but was not appreciated in importance until 1934 when Mettam assumed a possibility of heavy infection throughout domestic herds, at least in districts west of the Nile (Mettam 1935). In 1962 a high incidence was found in QENP in hippopotamus and buffalo; and to the east: eland, one zebra, and one giraffe, were found to be positive. Studies in Serengeti and in Zimbabwe produced further positive reactions in wild animals. In Zimbabwe black rhinoceros, warthog, buffalo, bushbuck, greater kudu (Br. melitensis only), eland, duiker, reedbuck, waterbuck, and impala, were positive. In Serengeti, zebra, buffalo, eland, waterbuck, Thomson's and Grant's gazelles, impala, topi, and wildebeest. Blackbacked jackal, wild dog, spotted hyaena, and lion, are also affected. Br. suis has been found in rodents in Kenya such as A. niloticus, $R$. (Mastomys) natalensis, and M. musculus. Screening of wild animals in Chad, Uganda, Tanzania, Zimbabwe, and South Africa, showed overall infection rates of 3.2\% in Chad, 8.3\% in South Africa, $10.5 \%$ in Zimbabwe, $11.1 \%$ in Tanzania, and $23.1 \%$ in Uganda (Thimm 1982), suggesting higher infection rates the more humid the climate. Among herbivores it appears often as epizootics. In Chad a high prevalence of antibodies was found in wildfowl such as ducks and geese, indicating that surface water has importance in the infection cycle. Evidence of cross-infection of strains of $\mathrm{Br}$. melitensis have been found in impala in Tanzania and sheep and goats in Kenya; and of Br. abortus in indigenous East African cattle and African buffalo, exotic cattle in East and South Africa, in a waterbuck in Zimbabwe, and buffalo in Kruger NP.

It has been shown experimentally that Brucella can multiply in ticks and remain viable in them for more than 2 years, passing transovarially to the next generation without loss of virulence, but usually transmission takes place by inhalation or 
ingestion. The brown rat in Morocco has been shown to pass on infection through its urine, infection by contamination of vegetation and food occurring in other locally numerous rodents passing infection on to domestic animals. Man requires close contact with infected animals to become infected himself.

Its ubiquitous appearance along lines of the known routes of introduction of different cattle breeds and their distribution by long range tribal movements in historical times, points to an adaptation of the Brucella family to the bovine species. Thimm (1972) speculates it was probably introduced into Uganda with Sanga cattle in the sixteenth century leading to an epidemic outbreak among indigenous human populations. Man to man direct transmission is rare and human outbreaks have always originated from animal reservoirs.

\subsubsection{Footrot}

Necrobacillosis is a common cause of epizootics of hoof infections in wild populations, especially in wet conditions. It has been implicated in Serengeti wildebeest and Kalahari gemsbok, the latter an arid country inhabitant. It has affected wildebeest calves in Selous GR causing lameness, tentatively identified as Spherophorus necrophorus. The infection could be of more importance in attracting predators to the lame animal than the effects of the lameness itself. Spherophorus is widespread in nature showing little or no host specificity occurring normally as a commensal in the intestinal tract. In cattle in South Africa necrobacillosis of the hoof is caused by a mixed infection of Fusobacterium necrophorum and Prevotella melaninogenica, whereas in small ruminants Dichelobacter nodosus with $F$. necrophorum and other bacteria are the cause; and in sheep $F$. necrophorum with Aerobacter pyogenes.

\subsubsection{Anthrax}

Anthrax is a fatal bacterial disease of worldwide occurrence present in soil caused by Bacillus anthracis. In 2004 outbreaks were reported in Ethiopia, Zambia, Zimbabwe, Botswana, and South Africa. Spores can survive in the soil for many years, are resistant to heat and chemicals and can withstand complete dessication, but usually germinate in most soils and are then very quickly destroyed in biologically active soils so they do not build up as might otherwise be the case. Outbreaks occur where the environment favours the persistence of spores, that is, the conditions do not favour germination. Animals are consistently exposed to relatively low doses of these persistent spores but are affected only when their resistance is lowered, as in the dry season. The spores usually enter the bloodstream through an abrasion but can be inhaled or ingested. In the bloodstream they multiply producing a toxin. Immunity can be acquired if an animal survives the disease but is 
not long-lasting. Anthrax can cause limited epidemics if it contaminates alkaline water, and it could be introduced with imported skins taken from animals which have died in an epizootic, or from skinning such animals, or contact with infected horses if a rider had sores or wounds rubbing against the horse's coat. Veterinarians have contracted it in the palm of the hand from inoculating herds of cattle, the skin becoming abrased and picking up the bacteria from the animal's coat. It has been known also to be contracted by ivory workers in Europe and America from infected elephant tusks (Spinage 1994).

There is an apparent reference to anthrax by Moses about 1300 B.C. when the Pharoah is threatened with an epizootic among his stock, "Behold the hand of the Lord is upon they cattle which is in the field, upon the horses, upon the asses, upon the camels, upon the oxen, and upon the sheep: there shall be a grievous murrain" (Exodus 9:3). From classical times into the Middle Ages many devastating epizootics were reported in Europe but these could have been often other diseases such as rinderpest. It was not until near the end of the sixteenth century it was suspected anthrax was transmissible to man. In 1613 it is estimated to have killed 60,000 people in an outbreak in southern Europe.

It seems it may have been first reported in Africa by Cadamosto near Senegal in 1454, referring to horses brought from Barbary the greater number of which die "from a malady in which they are unable to make water and so burst" (Crone 1937), but which Schotte (1782) translated as "seized with an obstruction of urine, attended by swellings in the groin", suggestive of equine anthrax. ${ }^{2}$ Livingstone (1857) encountered it in 1850 in Botswana terming it "horsesickness", with which he confused it, "Cattle, too, are subject to it, but only at intervals of a few, sometimes many, years; but it never makes a clean sweep of the cattle of a village, as it would do a troop of fifty horses... When the flesh of animals that have died of this disease is eaten, it causes a malignant carbuncle; which, when it appears over any important organ, proves rapidly fatal. . This disease attacks wild animals too. .." At Chonuane no fewer than 55 greater kudu died on the hill opposite his house, "Great numbers of gnus and zebras perished from the same cause, but the mortality produced no sensible diminution in the numbers of game...". He noted great numbers of zebras were occasionally found dead "with masses of foam at the nostrils, exactly as occurs in the common "horse-sickness"”, which produced a malignant carbuncle called kuatsi or selonda when the flesh was eaten. Silonda means an abscess or tumour in Lozi language, while kwatsi refers to anthrax in Tswana. In January 1854 in Lunda country he recorded that one of his men had two malignant pustules on his leg from eating a small portion of buffalo meat in the town of Quendende, "The disease cuts off very large numbers of the Barotse cattle occasionally, shewing that it prevails from Kuruman northwards. It is called Silonda" (Schapera 1963). It was reported in Cape Province in 1876 when it was referred to as "splenic apoplexy". In South Africa sporadic outbreaks have occurred in zebra, kudu, springbok, and hartebeest. In 1959-1960 there were over 1,000 mortalities in Kruger NP.

Rainfall particularly affects the susceptibility of animals to anthrax and a marked population decline in Kruger NP in 1990 of buffalo, and to a lesser extent greater kudu which declined by $20 \%$, was due largely to an anthrax outbreak. Outside of the 
enzootic areas in the Park, the Levubu and Limpopo drainages, localized to extensive epizootics have occurred in cycles of 6-20 years: in 1959-1960, 1970, and 1990-1991 in the north; and 1993 and 1999 in the central region. These occur in dry cycles and years of relatively high abundance of herbivores, evidence suggesting outbreaks are related to kudu densities when they congregate around stagnant water. Infection is spread by blowflies, mostly Chrysomya albiceps and $C$. marginalis which feed in large numbers on carcasses and which contaminate leaves in the vicinity fed upon by kudu (De Vos and Bryden 1996); while vultures, and to a lesser extent hyaenas, feeding on infected carcasses spread it by contaminating water points (Bengis et al. 2003).

Indications in Kruger NP are that epizootics occur in cycles of 10 years or multiples thereof, which coincides with the period of long term climatic cycles although no direct correlation has been demonstrated. It is speculated that climatic changes could have an effect through greater kudu which is the principal host of anthrax in Kruger NP. It occurs almost exclusively during the dry late winter and early summer months invariably terminated by onset of rain. Epizootics are dependent upon a certain density of kudu numbers in turn dependent upon climate. Northwards spread of an epizootic in 1990-1991 was interrupted by rain in November 1990 to April 1991, and again in November 1991 when the epizootic ended. Rain washes infection off the vegetation contaminated by infective saliva of feeding kudu or by blowflies, acts as a diluting factor, and washes it away into rivers and streams and fills waterholes, causing dispersal of animals and also provides vultures with alternative bathing areas.

Plotted curves of incidence show typical bell-shaped propagated epidemic curves indicating a short cycle of infection where disease is transmitted directly or indirectly from infected hosts, giving rise to an initial relatively slow multiplication phase followed by an exponential rise, and then as those infected die or recover the supply of susceptibles is depleted and the epidemic declines, terminated abruptly in the case of kudu by effects of rainfall. The pattern indicates the disease is density dependent and self-limiting.

Montfils (1776) suggested in France it might be caused by the bite of a "fly". Celli (1888) reported experiments purporting to show that it retained its virulence after passing through a fly's intestine, but it took Graham-Smith (1913) to demonstrate that spores could remain alive in the house fly Musca domestica and blowfly Calliphora erythrocephala for 20 days, and infective spores were passed out in the faeces. Contaminated dead flies remained infective indefinitely, and spores also passed via the larva to the imago. Infective spores could be carried on legs and wings for at least 10 days and could be alive still after 3 years. Moore had suggested in 1853 flies could be possible carriers (as well as of cholera, typhoid, tuberculosis, and leprosy), and Raimbert performed the first experiments using both biting flies and house and blow flies to demonstrate transmission by flies in 1869, placing them on infected material and then showing by inoculation of the legs, wings, and mouthparts, into guinea pigs that the bacilli had been present. The biting flies gave no result. 
Percival (1918) reported in Kenya it (ngar narua) was the most common disease among wild animals on Athi Plains and in Southern GR, a disease he had been aware of since 1903. Game died allegedly of anthrax in great numbers on the Athi in 1905, and at Oldonyo Sabuk and the Lukenia Hills where thousands of animals died, but it was confirmed first as anthrax during an outbreak among kongoni near Nairobi in 1918, breaking out in cattle at Mbagathi and spreading to the kongoni 7-10 days later, 300 dying in the ensuing 2 months, but no other animal was reported doing so. The Maasai insisted the same disease broke out every few years among game in one place or another, usually in the day season.

In Lake Manyara NP ecological conditions favourable to anthrax are present year-round. These are an alkaline soil with a $\mathrm{pH}$ greater than 6.0, an ambient temperature greater than $15.5^{\circ} \mathrm{C}$, high rainfall in the wet season with ephemeral swampy areas, and a dusty dry season which can spread spores in the atmosphere. The foci of infection are dried-up ephemeral water courses, hillside seep areas, and depressions where water has lain. An epizootic here in 1984 is estimated to have killed $92 \%$ of the impala population reducing it from an estimated 1,476 to 1,012 (Prins and Weyerhauser 1987). It spread at its fastest rate in August having begun 8 months before, levelling off in September and October. The impala began increasing in numbers again in November and December although the first calves appeared the previous August, acquiring immunity through the dam's colostrum, a recrudescence of mortality in October probably attributable to the calves losing their maternally derived immunity.

Baumann (1894) was the first recorded visitor to the area, marching up the west side of the lake through the present national park in 1892 he refers to the rich animal life but states also "the shores of the Manyara are flat and desolate". Crile (1937) and Crile and Quiring (1941) seem first to refer to impala, in 1935 in the area around Maji Moto, but give no indication of numbers except to state that they were coming right into the camp and, "... in front of us, the plain where herds of zebra, impala, and wildebeest graze"; "... in the grassy plain that edges the beach and in the bush near-by grazing giraffe, impala, reedbuck, wildebeest, zebra, ostrich, wart-hog, hyena, jackal, are always stirred up...”; “. . the impalas were so unafraid that we stopped the car to let them cross the trail...". And, "In plains near by [Maji Moto] were giraffe, eland, kongoni, impala, gerenuk, hartebeest, kudu, zebra, wildebeest, oryx, steinbok, Thomson's and Grant's gazelles, dik-dik and warthog”. Warthog, giraffe, bushbuck, steinbok, dikdik, reedbuck, Thomson's gazelle, and wildebeest were shot there, kongoni at Mto wa Mbu; but eland, kudu, Thomson's and Grant's gazelle, gerenuk, and oryx are not found there today. Watermeyer and Elliott (1943) noted impala were to be found in the glades in the forest "often in large herds" and in 1959 they were estimated to number 1,500-2,000. A "certain mortality", thought to be anthrax, occurred among the impala in this year, also killing zebra and wildebeest, and again in 1960 (Anon 1959, 1960). An outbreak of mortality in 1977 is believed to have been anthrax also (Prins and Weyerhauser 1987).

Prins and Weyerhauser observe that 1,400 impala were killed in 12 months while reported kills from predators in 28 months amounted to ten only, thus the effect of such epizootics is clearly important. The early references to impala suggest the 
population was able to withstand repeated high mortality without apparently becoming extinct, but extinction could have occurred and the area recolonized. The disappearance of some of the other species might be due to rinderpest while high lake levels might have driven out oryx and gazelles, and eland is probably an occasional visitor.

Prins and Weyerhauser considered mortality was not density-dependent as the disease was not transmitted between individuals, each animal picking it up from the soil at random. But the relation to density is complex, for the bigger the population the greater the chance of an individual picking up spores, and the greater the number of deaths the greater the surviving population of spores. To become infected it appears an impala must encounter a patch of infected ground or pool of water, and the spores must enter the blood stream through internal abrasions. Close grazing of tough scratchy forage in dry times can result in such abrasions in the mouth. Tough and closely cropped swards have their largest extent at the end of the dry season and depend upon the size of the herbivore populations using them. Infection in the intestinal tract may take place via lesions caused by internal bloodsucking parasites such as Haemonchus spp., parasite loads increasing also in the dry season when the host is weakened, and with host density. In Kruger NP, while other species succumbed heavily in outbreaks, impala mortality was minimal.

Nachtigal (1879-1889) reported an epizootic disease which had claimed many victims already among hippopotamus in Lake Chad in January 1872, “Almost every day we came across corpses of these colossal creatures, either fresh or already halfreduced to skeletons, and just as frequently we saw sick animals"; which appears to be the first probable record of anthrax in hippopotamus. Fyrth reported the death of some 20 hippopotamus in Zululand in 1897 (Thomas and Neitz 1933) probably from this cause. A fatal epizootic among hippopotamus in the Kasai River, DR Congo, was reported to have taken place about 1904-1905 (Hilton-Simpson 1911) which seems likely also to have been anthrax. In early 1932 "a mysterious disease" killed numbers of hippopotamus at the south-east end of Lake Albert, 60 dead being counted at one time. The cause was undetermined but again was probably anthrax. The following year a similar outbreak of disease occurred in Lake George killing at least 50-70. Some carcases floated down the Kazinga Channel but did not infect herds in Lake Edward. According to native report some animals came out on land with blood issuing from the mouth and nostrils (Pitman 1934). At the end of May 1937 a number of carcases, 17 were counted, was seen floating down the Kazinga Channel from Lake George, but again no deaths were reported in Lake Edward (Pitman 1938). In February and March 1941 unexplained mortality on a considerable scale occurred in the Uganda reach of the Semliki River, hippopotamus deaths having been recorded near the river's exit at Lake Edward at the beginning of February. In July to August mortality occurred also at the southern end of Lake Edward, still taking place in March 1942. Further mortality was reported on the DR Congo side in 1944. In March-April many deaths occurred in the lower Rutshuru River in Virunga NP. Following an exceptionally low Nile in 1944, mortality on a considerable scale occurred in December 1945 between the Lake Albert delta and Murchison Falls, several hundred carcases 
floating into the lake. Mortality continued into 1946 and it is estimated 1,000-1,500 hippopotamus perished.

In July-August 1946 there were many deaths in the Kazinga Channel, parts of Lake George and Lake Edward, with deaths were still taking place in the Kazinga Channel in February 1947 (Pitman 1949). In the now QENP in 1956 there was a suspected outbreak of anthrax when more than 80 hippopotamus died. It appeared to spread inland from the Lake Edward lakeshore at Lion Bay where there was a high population concentration, and mortality was particularly high in two inland wallows. The disease was observed to break out suddenly, taking a regular toll over 6 weeks and then stopping abruptly, not spreading from the small area affected. Mortality was mainly among adult animals and was estimated at about $15 \%$ of the population in the affected area (Bere 1957). Mud samples from wallows and samples of bones were examined in 1958 but all proved negative (Guilbride et al. 1962). Further outbreaks were suspected in 1959, 1962, 1991, and a confirmed outbreak beginning in Lake George in August 2004, the latter being the most devastating recorded culminating in a total of 317 known deaths, representing $16 \%$ of the then population estimated at 2,000. An estimated 60 buffalo representing $0.9 \%$ of the population, and a few elephant, warthog, kob, and waterbuck, succumbed also. As attempts were made to limit spread the outbreak may have been more extensive if it had been allowed to run its course.

Again carcases were seen floating down the Kazinga Channel but there was no outbreak in Lake Edward. Drought conditions prevailed at the time of the mortality and hippopotamus were seen eating the decaying carcases, pulling out decomposing entrails and consuming them for their vegetative content. It is believed this spread infection originally contracted by perhaps one or two hippopotamus stirring up spores in lake mud or inland wallows. Anthrax was clinically confirmed as cause of death and it is clear that this is a recurrent event among hippopotamus.

An outbreak at Lake Mburo apparently began in 2003 causing isolated deaths among zebra, confirmed as anthrax in 2005 when a total of 63 deaths was recorded representing $1.5 \%$ of the population (Wafula et al. 2007).

An epizootic occurred in Luangwa NPs in 1987, and although cases continued to 1988-1989 there was no further epizootic. This was the first reported here but earlier outbreaks may have gone undiagnosed. Several other species died, possibly in substantial numbers, especially elephant.

In October 2001 in Ivory Coast Taï NP, an area of tropical rainforest, a group of four chimpanzees died, and in the middle of 2002 a further four, all apparently in good health shortly beforehand. Autopsy revealed death was from respiratory and gastrointestinal anthrax, providing the first isolation of anthrax from this habitat (Leendertz et al. 2004). Six which were sampled were all positive for the $B$. anthracis strain of African origin. No mortality among other animals was observed and the mode of infection of the chimpanzees was not determined. B. cereus was present also, a related also widely distributed species which can cause food poisoning and wound sepsis in man. In January 2005 the first death from anthrax in a gorilla was reported, one gorilla and three chimpanzees dying in tropical forest in Cameroun. 


\subsubsection{Tuberculosis}

Tuberculosis is caused by mycobacteria which grow inside cells of the immune system, the macrophages which normally destroy bacteria and other pathogens. Evidence of Mycobacterium tuberculosis is found in ancient Egyptian mummies of $c 1200$ to 1000 B.C. (Brier 2004) and appears from molecular analysis to be a very ancient human pathogen, arising in Africa well before evolution of bovine tuberculosis $M$. bovis bTB from which it was once thought to have derived, thus suggesting the scenario that cattle were infected from man, and thus badgers must have been infected from cattle. The European badger is infected by the "classical" strain (Brosch et al. 2002).

$M$. bovis has at least six strains, among which specific hosts are the oryx, goat, and seal. A type conforming to bTB was first isolated from a wild animal in ground squirrels Citellus beecheyi in California in 1910, found in five in 225,000, thus rare although apparently widely spread it was believed to have been contracted from cattle (McCoy and Chapin 1911). Most of the evolutionarily old strains affecting humans and deriving from a common ancestor, such as $M$. canetti a very rare variant found in man in Africa, "ancestral" M. tuberculosis, and M. africanum, are of African origin. Splitting off from the $M$. africanum lineage, $M$. microti infects voles (and has been found in HIV patients also). Griffith (1928) isolated human strains from advanced tuberculosis in a captive wildebeest and a blesbok, observing that wild ruminants in captivity are apparently susceptible to the human type, in contrast to domesticated cattle and goats which are highly resistant to it.

Reference to human TB is made in fifteenth century B.C. Indian writings. Hippocrates encountered it in Greece in the fifth century B.C., and Aretaeus in the first century B.C. in Cappadocia. The Goths are credited with declaring it a contagious disease. The disease in animals was recognized in Mosaic Law which prohibited consumption of meat of animals suffering from "wen or scurvy". Frankish eccelsiastical laws of the ninth century forbade consumption of flesh of cattle and pigs with tuberculosis, and similar laws were enacted in Germany in the fourteenth and sixteenth centuries, indicating the disease was widespread in both man and domestic animals. In 1898 it was demonstrated that human and bovine tuberculosis were caused by separate but closely related organisms (Smith 1898).

Where leprosy, which is also caused by a mycobacterium, is present, TB is not present and vice versa, but although TB protects against leprosy, the converse is not the case. In Nigeria where leprosy was very prevalent, TB was rare. Livingstone wrote in 1843 that he saw TB prevailing very extensively among Hottentots in South Africa, especially those near the coast, but saw only one case in Botswana (Chamberlin 1940). In Angola it was one of the most common and widespread diseases by the nineteenth century and a regular cause of death from the 1850s (Dias 1981). In 1996 South Africa's Western Cape region had one of the highest incidences of human TB in the world and in Botswana most people are likely to have been infected by adulthood. Concurrent HIV infection may shorten the time 
for TB infection to develop into overt disease, and helminth infections may decrease the host immune response to TB leading to activation of latent infection.

M. tuberculosis was responsible for an epizootic among suricates Suricata suricatta from October 1998 to December 1999 in the southern Kalahari Desert of South Africa, when an unknown infected male joined a group of 20. A human case was known to live in the vicinity. North of the Kalahari Desert at Chobe in northern Botswana an epizootic broke out among banded mongoose Mungos mungo from June to September 1999 spreading to six troops, the first infected troop habitually scavenging in refuse tips in an area where there was also known to be a human case (Alexander et al. 2002). The ability of wild animals to maintain infection of M. tuberculosis in the absence of human reservoirs is unknown.

In South Africa in 1929 M. bovis was reported from greater kudu and bush duiker and allegedly seen in bushbuck. The animals were from a lightly stocked area where incidence in cattle was very low. The first suspected case in a kudu was in September 1927 and evidence subsequently found in another specimen. A total of four infected animals was shot up to July 1928, in which latter month a sick duiker was encountered and found to be infected also, tests indicating the bacilli were of the bovine type (Paine and Martinaglia 1929). Thomas and Neitz (1933) reported that in Albany District, Cape Province, it had been definitely proved to occur in kudu and duiker, in the former quite extensively and with considerable loss of life. It appeared to occur in the baboon also but had not been clinically demonstrated. It was identified in giraffe and springbok in South African zoos in 1930 and 1953 respectively. Bone lesions indicative of bTB in red lechwe from the Kafue swamps were reported in 1958 (LeRoux).

It is believed to have entered Kruger NP about the 1960s, initially transmitted to buffalo by infected cattle on the southern boundary and then spreading north at about $5 \mathrm{~km} /$ year with up to $60 \%$ of a herd infected, causing accelerated mortality in calves and yearlings. It spilled over into baboons, honey badger Mellivora capensis, genet cat, leopard, lion, cheetah, warthog, and greater kudu, but only bovids and possibly warthog appeared capable of maintaining the infection (Bengis et al. 2003). In areas with a high prevalence of infection in buffalo, $90 \%$ of lions were infected, indicating that it spreads quickly in lion populations. Long-term effects are unknown, and how far it will spread, and it poses interesting questions as to why this spread began when it did and how it differs from the ætiology of the disease in other parts of Africa. But although regarded as a recent introduction into wild animals in Kruger NP, Cleaveland et al. (2005) consider better livestock control in South Africa may have limited contact with wild animals and it has probably been present in wild animals for as long as it has been present in African cattle.

Of the infected lions more than $97 \%$ were positive for feline immunodeficiency virus FIV, but in Hluhluwe-Umfolozi NP bTB has caused severe pathology in the lions which are all free of FIV, suggesting FIV may not facilitate infection, contrary to HIV infection and TB in man.

In autopsies of 600 ungulates in Serengeti NP and Lake Rukwa areas in the 1960s Sachs failed to detect overt evidence of bTB infection (Woodford 1972), but at the end of the 1990s it was detected in a wide range of ungulates and carnivores in 
Serengeti and Tarangire areas, present in lions in Serengeti for at least 20 years (Cleaveland et al. 2005). M. bovis was found in $4 \%$ of lions $(\mathrm{n}=263), 6 \%$ of buffalo $(n=17)$, one lesser kudu $(n=1), 11.1 \%$ of topi $(n=9)$, and $11.1 \%$ of wildebeest $(n=18)$. It has been recorded in giraffe and eland also. No infected wildebeest showed detectable lesions at autopsy and were therefore unlikely to be excreting high levels of the mycobacterium and thus probably not maintaining it, but it is possible the disease could be transmitted to carnivores through consumption of infected tissue. Infection has been recorded in 2\% of Maasai cattle to the south and east of the Serengeti plains and transmission between wildebeest and cattle is possible. In Kenya's Mara area it was isolated from olive baboon Papio cynocephalus anubis in 1985.

M. bovis was found in 8-13 buffalo examined in QENP in 1963, thoracic lesions indicating infection was by inhalation. In a sample of 90 warthog, which appeared outwardly in good condition, $8.8 \%$ were infected, four confirmed as $M$. bovis, the other four were atypical mycobacteria (Guilbride at al. 1963). Thurlbeck et al. (1965) found four of five apparently ill buffalo examined there had chronic lung disease which they attributed to bTB, and one appeared to have an Actinobacillus lignierisii infection of the lung, an ubiquitous sporadic bacterial infection not usually associated with the lungs. Woodford (1972), in studies conducted about 1970 , found $10 \%(\mathrm{n}=52)$ of buffalo collected at random were infected with bTB, and from $20 \%$ to $55 \%$ of those selected as old or debilitated in appearance. The map, Fig. 23.1, shows the incidence of infection in different sectors of the Park. A high incidence, 5-34\%, was reported in cattle in adjacent Ankole in 1937-1941, and $44 \%$ of slaughterhouse samples in 1962. Thus the incidence around QENP was extremely high. No infection was noted south of the Maramagambo Forest where according to local report no cattle were known to have been kept historically. North of the forest was historically a dense cattle-keeping area until destroyed by raids in 1871. Stanley (1890) found the plains empty of cattle in 1889 but areas were rich in sheep and goats. Woodford (1972) found no evidence of bTB in a sample of 420 sheep and goats (about $25 \%$ of the total) from villages in the Park. Cattle populations which returned to the area after the assumption of British control were then affected by nagana and most were either dead or removed by 1924, a total of 15,000 being reported as removed that year (Spinage 1982). The last herd of 200 left the northern side of the Kazinga Channel in 1928.

Did infection remain enzootic in buffalo (the majority allegedly dying in the rinderpest epizootic of 1890), or was it contracted from cattle herds kept to the east between the 1930s and 1950s?

Bindernagle (in Woodford 1972) estimated from visual autopsy examination that 4\% $(\mathrm{n}=368)$ of buffalo cropped at Aswa, northern Uganda, in 1964-1967 were infected. Dalimier (1955) claimed tuberculosis rarely affected buffalo in DR Congo but without providing any supporting data, and Mammerickx (1960) while stating that it has been reported in buffalo everywhere "but it seems that the buffalo is rarely infected" does not make clear to what buffalo he is referring.

$M$. avium, M. phlei, and M. terrae, members of a worldwide group described as non-tuberculous bacteria causing paratuberculosis or Johne's disease, a chronic 


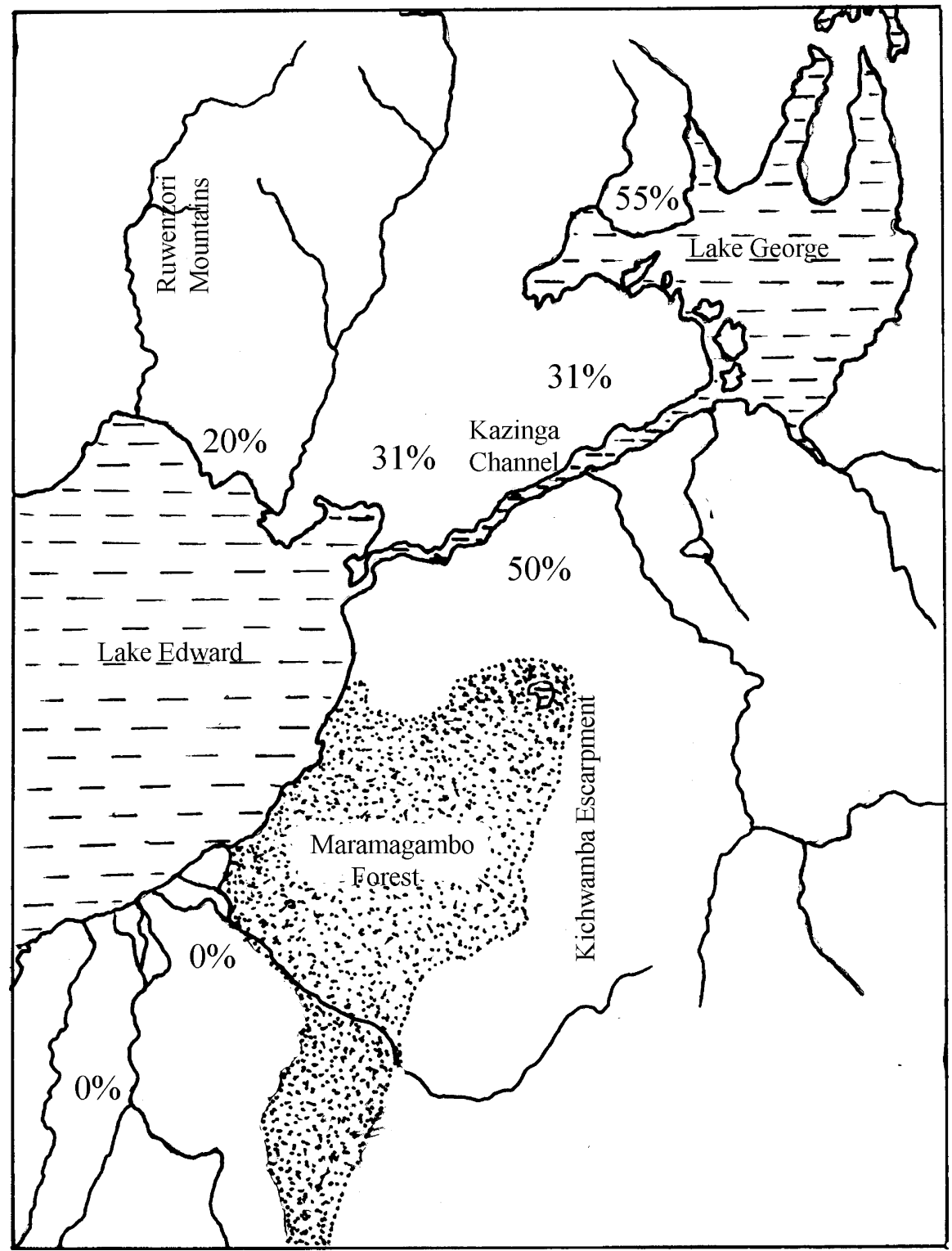

Fig. 23.1 The distribution of tuberculosis in African buffalo in Uganda's Queen Elizabeth National Park showing percentage incidence in samples (After Woodford 1972)

infectious disease, were found in wild animals in Serengeti. M. avium can cause clinical disease in some ungulate species and has affected buffalo in Serengeti. $M$. phlei and $M$. terrae are generally considered non-pathogenic in most species but in Tanzania have been associated with lesions in both cattle and humans. 
Paratuberculosis was found in a black rhinoceros in Kenya that had been in captivity for 2 years.

\subsubsection{Rickettsias}

Rickettsias are now classified in the phylum Proteobacteria, intracellular parasitic microorganisms suggested to have been originally diseases of insects which became adapted to a vertebrate host. Mostly occurring naturally in the tissues of arthropods they are transmissible to man and animals causing fever. In northern Botswana, Carmichael and Hobday (1975) examined buffalo (190), eland (1), kudu (16), red lechwe (13), impala (23), tsessebe (18), wildebeest (10), and sable antelope (11) for blood parasites, and the tick-borne rickettsia Anaplasma marginale causing gall-sickness in cattle was found in buffalo only (27.8\%), although anaplasma-like bodies were found in kudu, lechwe, impala, and sable antelope, also, but their significance was not determined. Anaplasma has been found rarely in buffalo elsewhere, there were two isolations in Kenya, one resembling A. centrale, and it has been rarely isolated from antelope. The giant rat C. gambianus was found naturally infected in Nigeria but tests on the same species in South Africa were negative.

In CAR buffalo were found to have antibodies to several rickettsias, reacting to epidemic typhus Rickettsia prowazeki, endemic (murine) typhus R. mooseri, African tick typhus $R$. conorii, Q fever Coxiella burnetii, and a Neorickettsia species, Q18. They were found also to have infected monkeys, carnivores, bushpig/warthog/ foresthog, and antelopes; with the exception of Q fever absent in the carnivores examined. Elephants were found to have been exposed to Q fever only (Thal 1972). In Selous GR strong exposure to $\mathrm{Q}$ fever was found to have occurred in impala (37\%) although no lesions associated with this infection were observed, and less so in hartebeest and wildebeest (Gainer 1979). Studies in Kenya isolated the causal organism of $\mathrm{Q}$ fever from the ixodid ticks Hyalomma leachii, Rhipicephalus sanguineus, and $R$. simus.

\subsection{Viral Diseases}

\subsubsection{Family Paramyxoviridae}

\subsubsection{Canine Distemper Virus CDV}

Canine Distemper Virus or CDV of the genus Morbillivirus, closely allied to rinderpest, can cause $90 \%$ mortality in some carnivore species. Percival (1918) reported it erupting among jackal (presumably side-striped jackal Canis adustus) 
and sweeping the whole country east of the Kikuyu Escarpment in Kenya in 1906. Jackal died by the hundred and most of the stray dogs in Nairobi died also. He could find no proof that hunting dogs or hyaenas had died but subsequently they appeared much scarcer for a few years. A year or two later the disease spread into the Rift Valley killing jackal and Wandorobo hunting-dogs. Several outbreaks occurred subsequently, as in Laikipia.

The complexities of disease transmission are illustrated by an epizootic of CDV in Serengeti which in 1994 killed a third of the lion population, but the population recovered rapidly. Between 1984 and 1988 CDV prevalence had declined from about $75 \%$ to zero, the former level believed to reflect a previously undetected epizootic. An epizootic in the 1980 s is thought to have corresponded with only 70 susceptible individuals, whereas that in 1994 did not emerge until all of the population of 250 lions was susceptible. This implies that infection existed in other species in the early 1990s so that the pool of susceptibles in the ecosystem was far larger than it had been in the 1980s (Packer et al. 1999). Spotted hyaena and wild dog also experienced high morbidity and mortality from the disease in 1994, which may have been facilitated by severe drought in 1993 bringing animals together at water points, as well as the animals being stressed and having lowered resistance to high levels of coinfection with other pathogens.

The wild dog became extinct but returned in 2005 .

The discontinuous spread of the infection in 1994 with long distance leaps in the lions, a territorial familial group species, suggested transmission by other more mobile species such as hyaenas and jackals which track lions and were found to be infected also (as were other carnivores such as domestic dog and bat-eared foxes), all of which could be infected in different ways according to their social behaviour. The leopard is likely to contract it only by contact with infected prey such as a dog, and although it might then infect a mate, the general solitary nature of this species means the infection would most likely be dead-end. With lions, one infected animal may infect several others, and they may infect both hyaenas and jackals which could carry it to other lion populations.

Thus differences in social structure can significantly influence the size, velocity, and probability, of a multi-host epizootic. Social structures which permit higher intraspecific neighbour to neighbour transmission are the most likely to transmit to other species, and species with low neighbour to neighbour interspecific transmission are most vulnerable to transmission between different species. In the 1994 lion epizootic hyaenas and/or jackals could have acted as amplifying species by spreading the virus to the more isolated lion prides causing long-distance leaps in infection.

Thomas and Neitz (1933) commented on "the mysterious decrease for no apparent reason" of wild dogs in South Africa. This was probably caused by CDV. 


\subsubsection{Family Retroviridae}

\subsubsection{Feline Immunodeficiency Virus FIV}

One of the few studies of viral infection in a wild animal population is that of Packer et al. (1999) on lions in Serengeti and the Ngorongoro Crater. Other than the presence of CDV, five other viruses were studied: feline immunodeficiency virus FIV (a member of the Family Retroviridae which includes HIV and a number of other genera affecting a wide range of birds and mammals); felid herpesvirus (herpes viruses affect a wide range of mammalian hosts including elephant, zebra, and wildebeest); feline parvovirus (there is a number of related parvoviruses one of which is ubiquitous in pigs throughout the world); feline corona virus (corona viruses are widespread in nature); and feline calcivirus (worldwide in domestic cats and also isolated from captive cheetahs). Feline leukaemia virus FeLV was not found. With the exception of corona virus, which may be transmitted by ticks or mosquitoes, these are not known to be arboviruses. Infection of FIV is by blood (through biting), herpes orally and by aerosol, parvovirus orally, corona virus and calcivirus orally and by aerosol. All populations showed consistently high levels of seroprevalence, indicating previous exposure to FIV and herpes and that chronic infection was enzootic. All but two of 374 lions had been exposed to herpes, including eight cubs less than 1 year of age. The other viruses were absent from the populations for periods of 4-12 years followed by resurgence, indicating epizootics took place, the sporadic nature being most evident in the youngest age classes. The precise timing of each outbreak differed between the Serengeti and Ngorongoro populations. Calcivirus was absent from the relatively small and isolated Ngorongoro population, as was parovirus among immature but not adult Ngorongoro lions. Parovirus, coronavirus, and calcivirus, varied significantly over time among immatures in the Serengeti, indicating epizootic outbreaks. In the Serengeti, corona virus and parovirus infection occurred typically in years of high lion population density. Almost every lion was FIV positive by the age of 4 years, and about $80 \%$ of 1-2 year olds. None of the viruses appeared to consistently affect fecundity but there could be strain differences. A high annual variation around the 1990 calicivirus and 1993 coronavirus epizootics the authors found difficult to interpret, suggesting it reflected other ecological factors such as annual variation in prey availability, population density, and social dynamics. Cub survival was significantly reduced during a calcivirus outbreak in 1980, but although survival was below average in a 1985 outbreak, cubs enjoyed higher survival than average than they did in a 1990 outbreak. The enzootic FIV and herpes had no apparent effects upon the populations. None of the epizootic viruses consistently lowered host fitness but the 1980 calcivirus outbreak may have inflicted considerable cub mortality. Other outbreaks appeared harmless, this apparent lack of pathogenicity possibly due to strain differences. Nothing is known of the reservoirs of these viruses, their mode of transmission from the reservoirs, nor their prevalence and 
effects in other species. The epizootic nature appears dependent upon the attainment of a threshold level of susceptibles.

\subsubsection{Family Herpesviridae}

\subsubsection{Malignant Catarrhal Fever MCF}

Malignant catarrhal fever or MCF is a herpes virus disease of worldwide distribution in cattle and numerous wild species which can cause more than $95 \%$ mortality and is sporadically epizootic. It occurs in three forms: European or sheep-derived, African or wildebeest-derived, the latter causing almost total mortality in cattle; and a recently isolated form in American white-tailed deer Odocoileus virginianus in which it is highly virulent, closely related to the sheep virus but of which the reservoir host has not been identified ( $\mathrm{Li}$ et al. 2000). In Africa it tends to be localized in occurrence, recurring at the same locality. The Maasai believed it was derived from wildebeest placenta and traditionally avoided wildebeest calving grounds, but research has shown that although post-natal wildebeest are infective the placenta is not the source. The virus has been isolated from the eyes and nose secretions of calves of a few days to less than 3 months of age. Older wildebeest have antibodies to the virus which is found within the cells of different organs. The calves are thought to contract it in utero and appear relatively immune. Transmission to cattle may be by aerosol or contaminated water or pasture, or possibly arthropod vectors. Cattle do not infect one another thus the disease is not epizootic. It has a long incubation period in cattle of 3-7 weeks, possibly longer, with most animals dying within 4-5 days of the onset of symptoms. Thus the cattle could move a considerable distance from the source of infection before succumbing. Some wildebeest, and probably cattle also, retain infection for life. A clinically pathogenic strain of the virus has been isolated from hartebeest A. b. cokei, and avirulent strains from topi and oryx, which might be carriers; but none of these three species has been implicated in the epizootiology of the disease.

Tests on 21 wildebeest calves abandoned by their mothers in Nairobi NP in the drought of 1961 yielded a single strain of MCF virus derived from a calf of less than 1 week of age. Reared together with eight others all acquired the virus by the 15 th week. Two bovine calves reared with the wildebeest acquired infection also after maximum incubation periods of 47 and 81 days, but further cattle exposed later did not become infected (Plowright 1965). Infection was highest in the wildebeest in the first 3 months when approximately one-third of all calves are viraemic at any one time, and the vast majority probably by 5-6 months. The method of spread from wildebeest to cattle and among wildebeest was not determined, and no virus was detected in urine when the virus level was high in the blood. Transmission by arthropods was discounted by Plowright on a number of grounds.

In Tanzania wildebeest calving is seasonal in December to February, and in eastern Kenya most calving is in February to April, thus the majority of infection 
should appear in February in Tanzania and April in eastern Kenya. In Tanzania presence of the disease is recorded only in January to May, peaking in March to April, while in Kenya it tends to peak in April to July. As viraemia falls after 3 months it does not occur after June in Tanzania and August in Kenya. Although it can be recovered from wildebeest of all age groups, all wildebeest over the age of 7 months in the three main population groups in East Africa possessed neutralizing antibodies, persisting at a high level throughout life. A proportion of calves acquire antibody very soon after birth and this is probably derived from the maternal colostrum, but about half of those examined did not do so. This may have been due to not obtaining colostrum during the critical 24-36 h after birth on account of separation from the dam, permanently or temporarily. Exposure to stress after birth from chasing by predators, particularly hyaenas, may inhibit antibody absorption. Passively-acquired antibody does not protect the calf from infection. Likewise recovery of virus from the blood of yearlings indicates that it is protected from neutralization, presumably by its intracellular location (Plowright 1967a). After the initial stage it is not transmissible to cattle which Plowright (1968) regarded as unusual hosts. It denies cattle access if wildebeest are present to the highly nutritious grass flush which emerges after the rains.

In the Selous GR traces have been found in impala and significant evidence in six wildebeest and one hartebeest screened.

Herpes viruses are often noted to be fatal when they cross over from one species to another. Zebras are primarily silent carriers of the Equine Herpes Virus EHV-1, a species which can affect Thomson's gazelle and which was responsible apparently for the death of a reticulated giraffe housed in a zoo in America with zebra positive for the virus (Hoenerhoff et al. 2006). A benign endotheliotropic herpes virus of the African elephant was found to cause fatal endothelial haemorrhagic disease in young Asian elephants when transmitted to them in North American zoos. The otherwise healthy African elephants with external herpetic lesions had herpes virus molecular sequences identical to that found in Asian elephants with the endothelial disease (Richman et al. 1999).

\subsection{Arboviruses}

Arboviruses do not comprise a natural group but are those viruses transmitted by arthropods, particularly mosquitoes, a cycle which appears essential for their maintenance and biological activity and which includes replication within the arthropod host. But a sufficient number of susceptible hosts must be produced annually to maintain the vertebrate-arthropod-vertebrate cycle. Some authorities no longer recommend the term arbovirus as it does not cover all arthropod-borne viruses, but the term seems to have stuck. It has been known for a long time that many, probably all, African mammals carry a number of arboviruses, the effects of which are unknown unless they happen to cause human fatality and that connection can be demonstrated. In southern Africa 15 new isolations were made between 1950 
and 1959 and a further 14 between 1959 and 1994 (Swanepoel 2004). Some 788 and rising have been identified worldwide but little is known of many of them, although more than 150 are known to cause disease in man, They are classified according to their DNA or RNA structure.

Vertebrates acquire infection generally through the bite of an infected bloodsucking insect. The insect is infected when it takes a blood meal from an infected vertebrate when the virus is circulating in its blood at a high enough level to be picked up. As Schlesinger et al. (1977) pointed out, this simplistic description tells us nothing about the nature of the totally different selective pressures in two host phyla so far apart on the evolutionary tree. The two way crossing of such disparate phylogenetic barriers makes it difficult to imagine a biological cycle more conducive to mutational and phenotypic changes, changes and pressures which have gone on for countless millennia. This has resulted, for example, in an apparently symptomless infection of vectors and in some cases specific forms of transovarial virus transmission.

The importance of arboviruses was shown in 1972 (Watson et al.) in a brief paper describing isolations from Palaearctic migratory birds intercepted in Egypt and Cyprus in 1966-1969, birds which travel from eastern Europe or western Asia and are channelled back and forth through eastern Africa. Mosquito and tick borne arboviruses were detected in passerine songbirds, quails, hawks, shorebirds, rails, doves, owls, and coraciiformes. Strains of the Bahig virus complex (Bunyamwera group viruses) were isolated from 15 species, but mostly from the European whitethroat Sylvia communis. Infections of autumn migrants suggest they were infected in eastern Europe or western Asia. Isolations from lesser whitethroat S. curruca, barred warbler S. nisoria, S. communis, European whinchat Saxicola rubetra, turtle dove Streptopelia turtur, redstart Phoenicurus phoenicurus, nightingale Luscinia megarhyncus, African barn owl Tyto alba, meadow pipit Anthus pratensis, lesser kestrel Falco naumanni, and spotted flycatcher Muscicapa striata, all proved pathogenic to mice, indicating the wide range of birds which can carry freely back and forth potentially lethal arboviruses. West Nile virus was isolated from barred warbler in Cyprus migrating north from Africa, and it has been found in a resident warbler, the longbilled crombec Sylvietta rufescens, in South Africa. In Uganda a sample of 221 birds showed 19\% had been exposed to Chikungunya, 15\% to Zika, and $13 \%$ to Ntaya, the latter a flavivirus causing encephalitis; in addition to the $43 \%$ exposed to West Nile. Birds are poor producers of neutralizing antibody but the highest incidence of West Nile antibodies was found in the dark-capped bulbul Pycnotus tricolor, one of the commonest birds in Uganda, especially around habitations. The highest number that had been exposed were bulbuls and weavers (Pycnonotidae and Ploceidae), birds of the savannah, such as grey-capped bulbul Pycnonotus tricolor, and fan-tailed widow-bird Coliuspasser axillaris. The highest number of birds testing positive for Zika virus were forest species, particularly little green bulbul Eurilla virens, most of which came from Budongo Forest.

In 1969 many positive results were obtained from monkeys in Bwamba forest suggesting an epizootic of Zika virus similar to one reported later in the Zika forest had occurred among forest vertebrates in the western forests of Uganda, but the 
incidence of Zika virus in bird samples in 1970 was low. A bee-eater Merops superciliosus was found to have been exposed to yellow fever and dengue as well as nine other arboviruses; as had the grey-capped bulbul also. The shrike Tchagra australis, sun-bird Nectarinia pulchella, weaver bird Ploceus cucullatus, and fantailed widow-bird, had been exposed also to these as well as to a number of other arboviruses (Okia et al. 1971).

As of 1972 of the 788 possible arboviruses recorded worldwide some 46, in addition to yellow fever, had been detected in CAR, of which 12 were confirmed arboviruses, 31 were possible arboviruses, and one was indeterminate (Dakar Bat) (Table 23.1).

Zinga virus has now been identified as RVF. In 1981 a strain of Saboya, a Flavivirus which is unknown to cause disease in man or animals, was isolated from the mosquito Ae. africanus sp. in CAR. In 1984 a relatively new virus termed Mobala virus, related to Lassa and Mopeia viruses of the Lassa complex, was isolated from M. natalensis and Praomys spp. in CAR but its disease potential and distribution outside of the identification site are as yet unknown. Mobala and Mopeia viruses are not known to affect humans.

In an apparently overlooked study conducted in CAR also, Thal (1972) obtained positive serum antibody responses to a wide range of arboviruses from a wide variety if animals, implying exposure of the animals to the viruses but not that they were hosts to them: Chikungunya, Sindbis, Middelburg, yellow fever, West Nile, Uganda S, Zika, Wesselsbronn and RVF; posing interesting questions about the ubiquitousness of these arboviruses and their hosts (Fig. 23.2; Table 23.2).

Also found in the north of CAR in 1971 were Gordil and Saint-Floris viruses, both named after the same location in the Sahelian zone and isolated from the same striped grass mouse L. striatus. Another isolate of the Gordil virus was made from a gerbil Tatera sp. Arumowot virus was recovered from Culex antennatus mosquitoes on the Nile in the Sudan in 1963, and from a rodent in CAR also, as well as from "insects" in Nigeria, Zimbabwe and South Africa. Nothing is known of the behaviour and life-cycle of almost all of these viruses and clearly these lists are just the tip of a massive iceberg.

The viruses were mainly in two groups (some 50 are known): group A comprised Chikungunya, Sindbis and Middelburg; while group B included the remainder, with the exception of ArB 1986 Zinga, which was newly discovered in CAR and believed pathogenic to man. Semliki Forest, Bouboui, Ar B 209, and Bunyamvera were also detected. The human population from the region, and in neighbouring Chad, exhibits a high percentage of antibodies to group B, including the very young. Chikungunya is of much lower incidence in the savannah than in the forest region, a pattern repeated in wild animals except for some very young ones. Both groups are widely spread in buffalo, while warthog and antelopes appear to indicate little exposure to group A. Elephants show considerable exposure to group B, but carnivores seem little affected. Thus large ungulates seem to be important in the savannah region but there is much less exposure in the forest. Very young animals show little or no antibodies which indicates the level is a function of the number of infective vector bites received.

Debbie (1970) also detected antibody responses to some of the same arboviruses from a number of animals in East Africa (Table 23.3). 
Table 23.1 Arbovirus isolations from Central African Republic ${ }^{\mathrm{a}}$

\begin{tabular}{|c|c|c|c|c|c|c|}
\hline \multirow[t]{2}{*}{ Name } & \multicolumn{2}{|l|}{ Origin } & \multirow[t]{2}{*}{ Arbovirus } & \multirow[t]{2}{*}{ Possible } & \multirow[t]{2}{*}{ Location } & \multirow[t]{2}{*}{ Habitat } \\
\hline & Arthropod & Vertebrate & & & & \\
\hline Bunyamwera & Aedes & & $*$ & & & \\
\hline Congo & & Man & * & & & \\
\hline Ingwavuma & Culex & $\operatorname{Bird}^{\mathrm{b}}$ & $*$ & & & \\
\hline Middelburg & Aedes & & $*$ & & & \\
\hline Mossuril & Culex/Aedes & Birds $^{c}$ & $*$ & & & \\
\hline Nola & & Man & $*$ & & Nola & Rainforest \\
\hline Pongola & Mansonia & & $*$ & & & \\
\hline Semliki forest & & Birds & $*$ & & & \\
\hline Sindbis & & & $*$ & & & \\
\hline Uganda & & $\operatorname{Bird}^{\mathrm{d}}$ & $*$ & & & \\
\hline West Nile & & & $*$ & & & \\
\hline Zika & Aedes & & $*$ & & & \\
\hline Arumowot & & Rodent $^{\mathrm{e}}$ & & $*$ & Bangui & \\
\hline Bangoran & Culex & Bird & & $*$ & Bangoran & \\
\hline Bangui & & Man & & $*$ & Bangui & \\
\hline Bimbo & & Bird & & $*$ & Bangui & \\
\hline Birao & Anopheles & & & * & Birao & \\
\hline Botambi & Culex & & & $*$ & Botambi & Forest clearing \\
\hline Boteke & Mansonia & & & $*$ & Boteke & Forest clearing \\
\hline Bouboui & Various & Bird/Rodent & & $*$ & Bouboui & Gallery forest \\
\hline Bwamba & & Man & & $*$ & & \\
\hline Dakar bat & & Bat & & $*$ & & \\
\hline Dugbe & Hard tick ${ }^{\mathrm{f}}$ & Man & & $*$ & & \\
\hline Garba & & $\operatorname{Bird}^{g}$ & & $*$ & & Dry savannah \\
\hline Gomoka & Anopheles/Culex & Bird & & $*$ & Bambio & Rainforest \\
\hline Gordil & & Rodent $^{\mathrm{h}}$ & & $*$ & Gordil & Dry savannah \\
\hline Ilesha & Anopheles & Man & & $*$ & & \\
\hline Kamese & Culex & & & $*$ & & \\
\hline Kolongo & & $\operatorname{Bird}^{\mathrm{i}}$ & & $*$ & Bangui & \\
\hline Koutango & & Rodent $^{j}$ & & $*$ & & \\
\hline Landjia & & $\operatorname{Bird}^{\mathrm{k}}$ & & $*$ & Landjia & Forest/Savannah \\
\hline M'Poko & Culex & Man & & $*$ & Bangui & Forest/Savannah \\
\hline Ndumu & Aedes & & & $*$ & Bangui & \\
\hline Ntaya & Culex & & & $*$ & & \\
\hline Nyando & Anopheles & Man & & $*$ & & \\
\hline Ouango & & $\operatorname{Bird}^{1}$ & & $*$ & Landjia & Forest/Savannah \\
\hline Pata & Aedes & & & $*$ & Pata & Forest/Savannah \\
\hline Pongola & Mansonia & & & $*$ & & \\
\hline Saint-Floris & & Rodent $^{\mathrm{m}}$ & & $*$ & Gordil & Dry savannah \\
\hline Sandjimba & & $\operatorname{Bird}^{\mathrm{n}}$ & & $*$ & Landjia & Forest/Savannah \\
\hline Simbu & Aedes & & & $*$ & & \\
\hline Tataguine & Anopheles & Man & & $*$ & & \\
\hline
\end{tabular}

The multiplicity of viruses to which these animals have been exposed probably provides them with cross-immunity. Thus it has been shown that vervet monkeys can be immunized against yellow fever with Wesselsbron virus and it has been suggested this and other arboviruses may produce an immunological barrier, preventing spread of yellow fever and limiting the distribution of some other virulent arboviruses (Nelson 1974). These results pose interesting questions concerning the life history of arboviruses and their vectors, the main vector probably being the mosquito, but 
Table 23.1 (continued)

\begin{tabular}{|c|c|c|c|c|c|c|}
\hline \multirow[t]{2}{*}{ Name } & \multicolumn{2}{|l|}{ Origin } & \multirow[t]{2}{*}{ Arbovirus } & \multirow[t]{2}{*}{ Possible } & \multirow[t]{2}{*}{ Location } & \multirow[t]{2}{*}{ Habitat } \\
\hline & Arthropod & Vertebrate & & & & \\
\hline Usutu & Culex & Bird/Rodent ${ }^{\circ}$ & & * & & \\
\hline Yata & Mansonia & & & * & Birao & Dry savannah \\
\hline Zinga & Mansonia/Aedes & $\begin{array}{l}\text { Birds/Rodents/ } \\
\text { Large mammals }{ }^{\mathrm{p}}\end{array}$ & & $*$ & Zinga & Forest \\
\hline Zingilamo & & $\operatorname{Bird}^{\mathrm{q}}$ & & * & Bangui & Forest clearing \\
\hline
\end{tabular}

${ }^{a}$ From Berge 1975

${ }^{\mathrm{b}}$ Orange-cheeked waxbill Estrilda melpoda

${ }^{c}$ Little green bulbul Andropadus virens, Blue-naped mousebird Colius macrourus, 'wild bird'

${ }^{\mathrm{d}}$ Whinchat Saxicola rubetra (Palaearctic migrant)

${ }^{\mathrm{e}}$ Striped grass mouse L. striatus

${ }^{\mathrm{f}}$ Tropical bont tick $A$. variegatum

${ }^{g}$ Blue plantain-eater Corythaeola cristata, Beautiful long-tailed sunbird Nectarinia pulchella

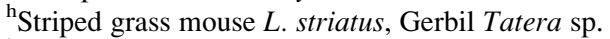

${ }^{\mathrm{i}}$ Yellow-crowned bishop Euplectes afer, Bronze mannikin Lonchura (Plesiositagra) cucullata

${ }^{\mathrm{j}}$ Multimammate rat Mastomys sp., striped grass mouse Lemniscomys sp.

${ }^{\mathrm{k}}$ African sand martin Riparia paludicola

${ }^{1}$ Black-headed weaver Ploceus (Sitagra) melanocephalus

${ }^{\mathrm{m}}$ Tatera sp.

${ }^{\mathrm{n}}$ Sedge warbler Acrocephalus schoenobaenus (Palaearctic migrant)

${ }^{\circ} \mathrm{Bush}$ rat Aethomys hindei medicatus

${ }^{\mathrm{p}}$ Buffalo, warthog, bushpig, giant forest hog, elephant, 'monkeys', hartebeest, 'other big mammals'

${ }^{\mathrm{q}}$ Piping hornbill Bycanistes fistulata (sharpii)

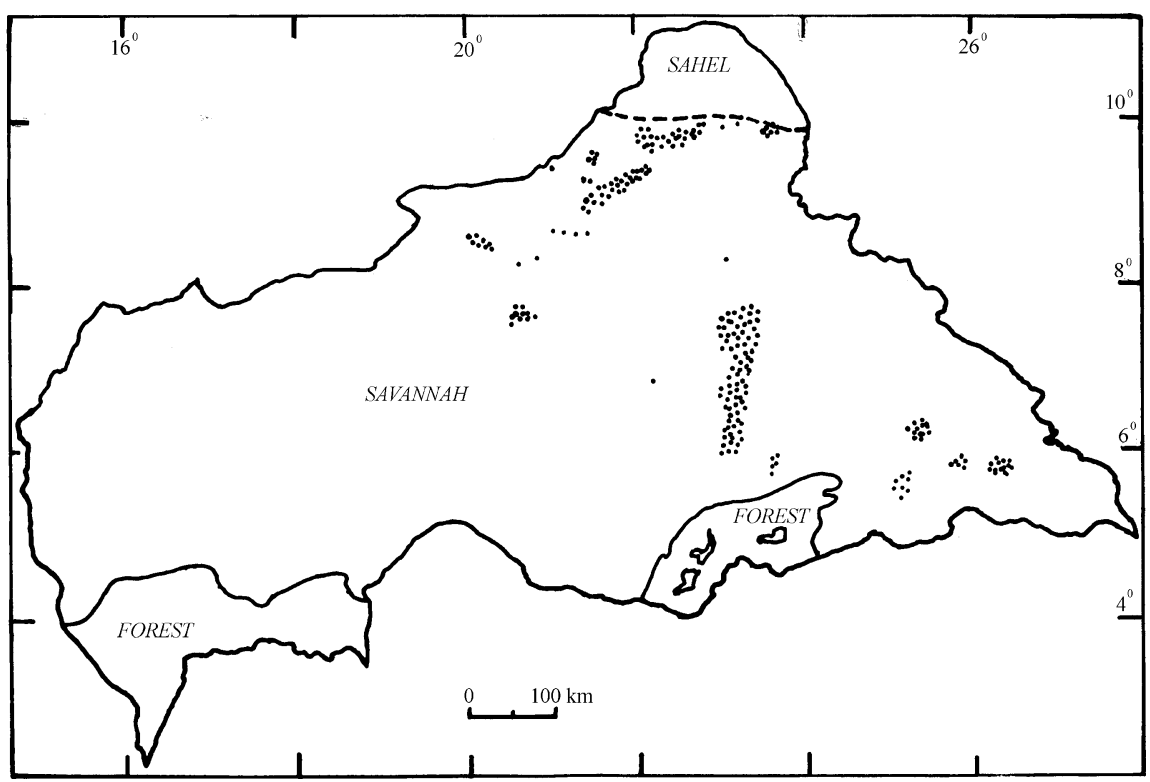

Fig. 23.2 The savannah region of Central African Republic, with arbovirus and rickettsia collection areas stippled (Based on Thal 1972) 


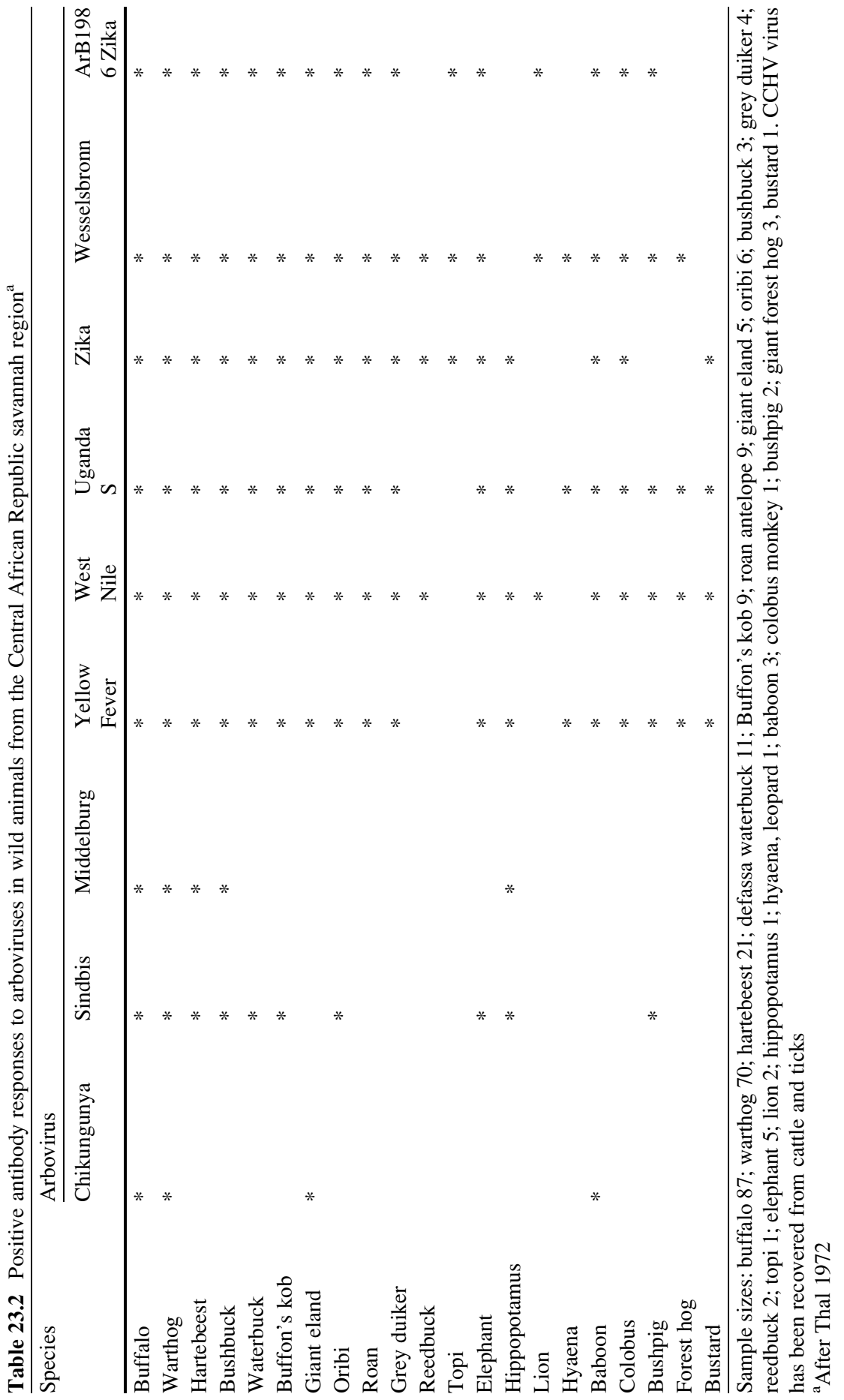




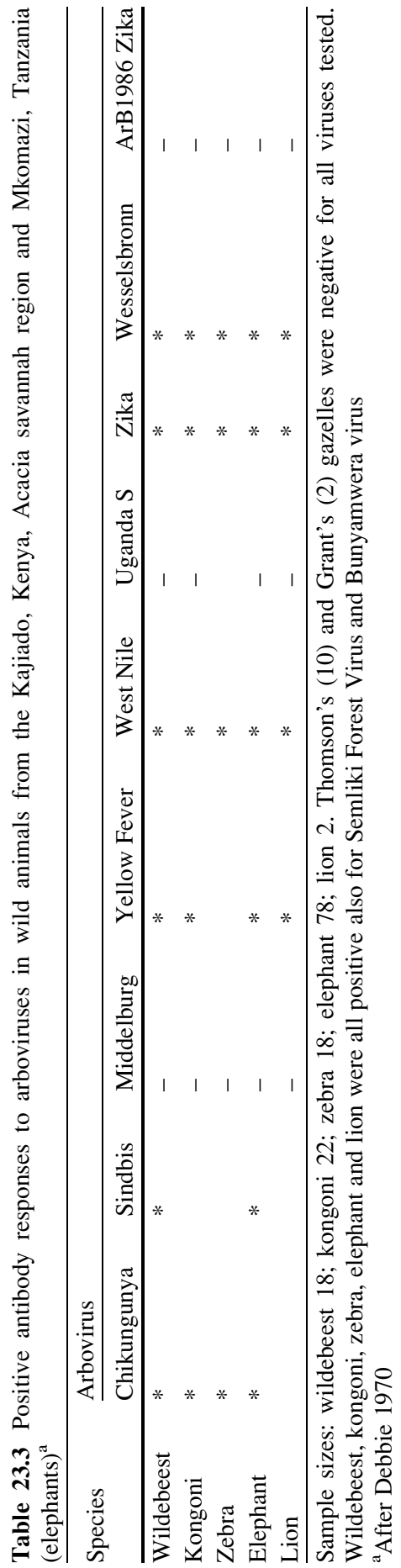


sources of the viruses for the most part remain undetermined. The wide occurrence of yellow fever, normally associated with forest primates, is surprising. And how widespread are these arboviruses among the African fauna? Do the herds of Serengeti wildebeest provide dense concentrations, or do such herds discourage vectors? The prevalence of buffalo exposure would suggest otherwise.

Is the hippopotamus infected by mosquitoes or ticks? In view of its close association with mosquito habitat it is perhaps not surprising the hippopotamus reacts positively for a number of arboviruses and has become adapted to resisting them, its sera containing a powerful anti-viral enhancing factor (Weinbren and Hewitt 1958). Hippopotamus from QENP showed exposure to yellow fever, Zika, Nairobi Sheep disease, Semliki Forest and Uganda S. Together with those reported from CAR this makes a total of at least nine species.

Between 1966 and 1970 a total of 7,497 small mammals from the major vegetation zones, rainforest, guinean, and sudanien woodland, south of the Sahara in Nigeria, Benin, and Togo, was examined for arboviruses, recovering 16 different types from 14 different animal species (Kemp et al. 1974). Of these, six were from the four-toed hedgehog A. albiventris and three from shrews Crocidura. spp. Multiple virus types were isolated also from Tatera kempi, A. niloticus, giant rat, and $M$. natalensis. A virus labelled SudAn 754/61 was the most frequently encountered, occurring in a primate Galago senegalensis, an insectivore A. albiventris and seven rodent species. Second in frequency was Arumowot recovered from an insectivore Crocidura sp. and three rodent species. Only one other, Bhanja, originally detected in India, isolated from hedgehog and ground squirrel Xerus erythropus and known from ticks and livestock in Nigeria, is not pathogenic to man. Bluetongue (type 7), Chandipura, originally isolated from India where it causes febrile illness and possibly fatal disease and which may affect livestock, has been recovered from the hedgehog Atelerix spiculus and man in Nigeria, and in Senegal from phlebotomine sandflies Phlebotomus spp.; Congo, Mokola, Semliki Forest, and an untyped virus IBAn 17143, were each exclusive to a single insectivore species. Uganda $\mathrm{S}$ was isolated from A. niloticus, $M$. natalensis, and giant rat. The giant rat hosted Dugbe virus also. Lebombo virus was found in the savannah cane rat Thryonomys swinderianus only; poxvirus, and an untyped virus IbAn 33709, in T. kempi, and West Nile in A. niloticus. The highest recoveries were made in the wet season and most in the sudanian woodland zone, Bluetongue being exclusive to the rainforest. Dugbe, Congo, and Bhanja viruses, are tick borne, frequently isolated from ixodid ticks and domestic stock in Nigeria. Congo virus, which can be fatal in man, appeared widespread in hedgehog which may be a possible reservoir. Lebombo originally isolated from the mosquito Ae. circumluteolus in South Africa, in addition to being isolated from $T$. swinderianus, was found in the louse Scipio aulacodi from the same host, from the mosquito Mansonia africana, and from a sick child. Mokola, isolated from shrews, may be pathogenic to man. Semliki Forest was isolated from the hedgehog. Uganda $\mathrm{S}$ has been isolated from mosquitoes and a sick child in South Africa, and its presence in a range of rodents may indicate a role in maintenance of the virus. The relevance of Bluetongue is not known. 
The pattern of occurrence in small mammals differs to that in large mammals as shown by Thal (1972) from similar latitude and vegetation types. In Uganda, Semliki Forest and West Nile were all isolated from hosts in forest habitat; but in Kenya these were isolated from inhabitants of open plains (Debbie 1970).

\subsubsection{Family Togaviridae}

Within the Family Togaviridae viruses of the genus Alphavirus occurring in Africa are found in four main complexes: Western equine encephalitis with Sindbis and Babanki; Semliki Forest with Semliki Forest, Chikungunya, Igbo Ora, and O'nyong-nyong; Middelburg and Nduma being sole representatives for each. Semliki Forest Virus was found in lion, kongoni, and wildebeest in Kenya, and elephants in Tanzania. It can be transmitted simultaneously with malaria by Ae. aegypti and this may apply to a number of other arboviruses also.

\subsubsection{Family Flaviviridae}

Flaviviruses of the family Flaviviridae found in Africa are yellow fever, dengue, West Nile, Banzi, Spondweni, Usutu, Wesselsbron, Ntaya, and Zika. Zika seems to be more of a savannah than a forest virus. Since its discovery in Zika Forest, Uganda, it has been isolated in CAR, Nigeria, Ivory Coast, Senegal, and exposed persons have been detected in Burkina Faso. It exists in a sylvatic cycle apparently through monkeys and is transmitted by mosquitoes, at least Ae. africanus, Ae. luteocephalus and Ae. opok.

Wesselsbronn is widely distributed in Africa causing epizootics resulting in abortion and maternal death of sheep but may be contracted by humans although no deaths have been recorded from it. It is transmitted by Anopheles caballus and $A$. circumluteolus. It exists in an enzootic state in Chad where $77.4 \%(\mathrm{n}=31)$ of wild animals tested carried antibodies to it, namely buffalo, Dorcas gazelle Gazella dorcas, red-fronted gazelle G. rufifrons, Dama gazelle G. dama, topi, hartebeest, and oryx (Maurice 1967). It was common in animals sampled in Kenya with the exceptions of Thomson's and Grant's gazelles which showed an apparent absence of arboviruses. It was present in $80 \%(\mathrm{n}=78)$ of elephants in Mkomazi, Tanzania. In South Africa high infection rates have been found in C. rubinotus mosquitoes of Banzi, Germiston, and Witwatersrand viruses, the mosquito being considered to be an efficient vector. 


\subsubsection{Family Bunyaviridae}

The Bunyaviridae is a relatively recently defined family of arboviruses structurally and genetically different from other arboviruses. Most exist in silent sylvatic transmission cycles. At least 168 of the known viruses are in the genus Bunyavirus of which 27 are African, four African-Asian, and two African-European; seven cause fever in humans while others cause disease of veterinary importance in animals. They take their name from the Bunyamwera virus isolated from Aedes mosquitoes in Bwamba, Uganda, in 1946, and since isolated also from Culex, Anopheles, and Mansonia species. Elephants in Mkomazi had a high incidence of Bunyamwera virus (72\%) which was found in lion, zebra, kongoni, and wildebeest, in Kenya.

A number of bunyaviruses, including Simbu, Tete, and Turlock serogroup viruses, has been isolated from resident and migratory birds which may account for their wide distributions, globally or continentally. Those viruses confined to single continents, e.g. Africa, may be so isolated because they replicate in mosquitoes, rodents, bats, and other mammals, but not in birds (Calasher and Nathanson 1995). Saboya virus was isolated first from a gerbil Tatera kempi in Senegal and then recovered from other rodent species, especially Mastomys spp., A. niloticus and M. musculus, particularly in the Sahelian region. Two strains were isolated from the mosquito Ae. vittatus also. Its isolation from sandflies in Senegal suggests a transmission cycle between sandflies and rodents (Fontenille et al. 1994). In Burkina Faso: Arumowot, Gordil, Saint-Floris, Gabek Forest, and Odenisrou, viruses have been isolated from cattle, sheep, and goats, but there was no evidence of pathogenesis.

Sindbis, isolated first in Egypt in 1952 and found since in a wide variety of mosquitoes, and in ticks, frogs, birds, bats, mice, wild hamsters, and humans. apparently hosted by birds, is transmitted by culex mosquitoes, Culex tritaeniorhynchus, $C$. pseudovishnui, and C. inivittatus in a bird-mosquito cycle. In South Africa, where it has been found in the masked weaver Ploceus velatus, in endemic areas up to $23 \%$ of people tested were found to have been exposed to it but the human vector is unknown. Even more widely distributed than Chikungunya it extends to Australia but has caused non-pathogenic disease in humans occasionally only. Differences between the virus in different parts of the world indicate evolution of the virus is taking place.

\subsubsection{Family Nairoviridae}

\subsubsection{Crimean-Congo Haemorrhagic Fever CCHF}

The 32 known viruses of the genus Nairovirus of the Bunyaviridae are transmitted by ixodid or argasid ticks. Of these three are pathogenic to man: Crimean-Congo haemorrhagic fever CCHF, Nairobi sheep disease, and Dugbe. Africa has the highest prevalence of CCHF virus in large herbivores, preferred hosts of adult 
Hyalomma ticks, and in small mammals which are considered to be preferred hosts of the nymphs and larvae. Mammals of intermediate size and passerine and water birds generally lack evidence of infection and birds appear to be refractory, but antibodies have been found in ostriches in South Africa the relatively high titres suggesting they may be more susceptible to infection than other birds, and there is a single record from an ostrich in Tanzania (Hoogstraal 1979). In Senegal the redbilled hornbill Tockus erythrorhyncus has been found experimentally to infect nymphal Hyalomma sp. although the birds failed to develop demonstrable viraemia. The virus has been isolated from the hedgehog A. albiventris in Nigeria from the savannah and on Jos Plateau, and from the Sudan. Hares are common carriers of the virus in Eurasia but although the African hares Lepus spp. play host to several tick species records of $\mathrm{CCHF}$ are lacking. Antibodies to the virus have been found in multimammate rat and genet cat $G . g$. senegalensis in Senegal.

It has been isolated from at least 30 species of tick, including 28 ixodid and two argasid, but not all have been demonstrated to be vectors. In general the distribution of Hyalomma ticks, which appear to be the most efficient vectors, in Europe, Asia, and Africa, coincides with distribution of CCHF virus. In Africa it has been isolated from at least ten ixodid ticks, several strains from Hyalomma ticks, up to eight from $H$. truncatum parasitizing cattle in Senegal, and two in Nigeria. Each of the ten species is typical of the Ethiopian Realm except $H$. anatolicum anatolicum which occurs south of the Sahara near the borders with the Palaearctic Region only; the others being $H$. impeltatum, $H$. impressum, $H$. m. rufipes, $H$. nitidum, $H$. truncatum, A. variegatum, $R$. pulchellus, $R$. appendiculatus, and B. decoloratus. $R$. pulchellus is the only African three-host tick involved in CCHF epidemiology in which rodents and insectivores appear to have no role as hosts in the immature stages. In Senegal and CAR CCHF, has been isolated many times from Amblyomma and Hyalomma ticks. Experimentally it has been found that replication and vertical transmission can take place in $H$. m. rufipes, H. truncatum, H. impeltatum, $H$. dromedarii, A. variegatum, A. hebreum, $R$. appendiculatus, and $R$. evertsi mimeticus.

Swanepoel (1995) considered the role of large mammals in transmission was theoretically limited by the fact they are hosts to adult Hyalomma in which transovarial transmission occurs with low frequency, hence the acquisition of infection by immature ticks on small mammals probably constituted the most important amplifying mechanism ensuring perpetuation of the virus, and facilitated trans-stadial transmission of infection by adult ticks to large vertebrates. But Spinage (1969a) found that two adult female defassa waterbuck from western Uganda carried more than 2.5 and more than four times as many nymphal and larval stages as they did adult ticks, while a male had 217 times more nymphal and larval stages on its legs than adult ticks, and the fore half of its body above the legs had 1,780 nymphs and larvae and no adult ticks. In all cases the species were mainly $R$. tricuspis and some $A$. cohaerens, but $H$. nitidum and $H$. rufipes have been recovered from waterbuck in CAR, and H. truncatum in Cameroun. In a study in South Africa van Dyk and McKenzie (1992) found nymphs and larvae outnumbered adult ticks on impala by more than twice, with an average total of 
all stages of around 1,500/impala. This suggests that by sheer numbers alone large herbivores are probably more important than small mammals or birds as possible amplifiers of CCHF infection. In the laboratory newborn wild rodents bitten by infected ticks can succumb fatally, but the role of $\mathrm{CCHF}$ virus in causing rodent mortality has not been investigated.

\subsubsection{Nairobi Sheep Disease NSD}

Nairobi sheep disease or NSD of the genus Nairovirus is one of the most pathogenic Bunyaviridae viruses for small ruminants in East Africa. It was isolated first from sheep in Kenya in 1910 when a large mortality occurred among sheep brought to Nairobi by traders from outlying areas of the district, the disease affecting essentially Kikuyu country between Mount Kenya and Nairobi but now, if not then, found in a narrow band from Kenya to DR Congo. Antibodies, but not the virus, have been found in Ethiopia and Somalia to the north, and south to Mozambique and Botswana. The main vector appears to be the tick $R$. appendiculatus. In 1954 it was shown to be the same as Ganjam virus isolated from ixodid ticks in India and suggested it may have been imported to East Africa with ticks on sheep traded from India since ancient times.

\subsubsection{Dugbe}

Dugbe virus was isolated first from ixodid ticks in Nigeria in 1964, and since then frequently from cattle and occasionally from humans with fever in West Africa. Some 600 isolations have been made from ticks, principally A. variegatum, in Nigeria, CAR, and Ethiopia, and the virus has been isolated from giant rat, Aedes and Culicoides mosquitoes, in Nigeria. There is also serological evidence of the virus in Senegal and Uganda, and it has been isolated from persons with benign fever in Nigeria and CAR, but widespread human infection has not been revealed.

\subsubsection{Family Phleboviridae}

\subsubsection{Rift Valley Fever Virus RVF}

Rift Valley Fever Virus or RVF virus is an arbovirus of the Bunyaviridae family, genus Phlebovirus, an antigenically stable arthropod-borne infection of animals primarily pathogenic for sheep, goats, and cattle. Two major DNA lines have been established, an Egyptian and a sub-Saharan (Sall et al. 1997). Widespread in the Sudan and many parts of East and Equatorial Africa, it exists in an enzootic state in Chad and Northern Cameroun as well as occurring sometimes in South Africa and sporadically overall in at least 24 sub-Saharan African countries. It appears to 
fluctuate according to long-term climatic cycles, wetter conditions favouring the mosquito vectors by which it is principally spread, including Eretmapodites, Aedes (Ochlerotatus), Culex, Mansonia, and Anopheles species, with a possible natural reservoir in a phlebotomine fly. It is passed in mosquitoes to the next generation through transovarial transmission, but in sheep experimentally by contact also. Buffalo may be susceptible to it and numerous wild animals were affected in an epizootic in South Africa in 1951. In Chad antibodies have been found in buffalo, reedbuck, red-fronted, Dorcas, and Dama gazelles, topi, and oryx. It is serologically related to the phlebotomus fever group and closely related to the Gordil and SaintFloris viruses. A disease fitting the description was described in sheep first in Kenya in 1911 (Montgomery 1910-1911) and it was described by Stordy in 1913 (although this may have been cobalt deficiency), but not isolated until 1931 when it was described in a newborn lamb following an epizootic in 1930 (Daubney et al. 1931).

From the lack of antibodies in a wide range of wild and domestic species in South Africa, Barnard (1997) infers it was not present there historically, but a major epizootic was experienced in 1951 causing the loss of 100,000 sheep and cattle when it was also contracted by man. Prior to the end of 1950 it was not known in South Africa until in December of that year there was a number of reports of heavy mortality in cattle and sheep in the western area of the Free State. By 1951 it was present in the Northern Cape and Southern Transvaal also, areas characterized by wet valleys, pans, and lakes, which were filled by heavy rains in 1950; but it is not known from whence or how the disease was introduced (Alexander 1951). Subsequent epizootics led to the surmise the disease was persisting in circumscribed enzootic foci, considered to be two heavily wooded areas on the Cape and northern Natal coasts, with epizootic spread triggered by exceptionally wet seasons favourable to the vectors (Swanepoel 1981). Both wild and domestic animals can survive the disease and thus act as carriers. Infected mosquito eggs must be thoroughly saturated with water before hatching takes place, larvae emerging only after heavy rains saturate depressions where these mosquitoes breed.

In Zimbabwe cattle tested in 1952 and 1955 were positive for exposure to the virus and $10 \%$ of aborted cattle fetuses were positive in 1957. This was followed by an explosive outbreak in sheep and cattle in early 1969 causing death and abortion and continuing until 1970. Although epizootic areas have been identified in both Zimbabwe and South Africa these may simply reflect the main stock rearing areas. In 1969 there was a large outbreak in Mozambique to the east, and in 1974-1975 there were widespread epizootics in South and South-West Africa. Routine screening showed continued presence of the virus in Zimbabwe in inter-epizootic years, the next epizootic accompanying particularly heavy rains in 1978 when it is estimated to have killed $3 \%$ of the national herd. If affected females survive the infection they commonly undergo spontaneous abortion, virtually all pregnancies being lost in the Zimbabwe outbreak. McIntosh and Jupp (1981) claimed there was a reasonably good correlation between outbreaks and periods of higher rainfall in South Africa from 1938 to 1978, predicting a high probability of severe outbreaks again in the 1990s based on predictions of rainfall cycles. In fact there was one 
serious outbreak in 1996. Periods of heavy rainfall in Kenya have been correlated with outbreaks also.

Sampling since 1955 of Culicoides spp., Simuliidae, Phlebotominae, and other biting Diptera, failed to reveal the virus, which has been isolated from mosquitoes only. Studies suggested $C x$. theileri is the main epizootic vector among domestic ruminants, while Ae. juppi, Ae. lineatopennis, and possibly other mosquito species, play a lesser role. $C x$. theileri is the most prevalent and widespread mosquito in the epizootic area, is relatively resistant to aridity, and feeds mainly on sheep and cattle, which have probably supplanted its former wild hosts. It feeds readily on man also. Little reliable evidence was obtained in Natal to implicate mosquitoes as vectors of the enzootic infection among cattle in the coastal region, and no evidence was obtained to suggest mosquitoes were involved in maintenance of the virus, but Ae.circumluteolus, C. zombaensis, and Er. quinquevittatus, were considered probable incidental vectors. In the 1930 epizootic in Kenya a high mortality among rodents A. abyssinicus nairobice and $R$. rattus kijabius was noted, but evidence of the virus is rare in sampled rodents, although antibodies have been found in a wide range of species throughout sub-Saharan Africa, from Senegal and Niger through East Africa and Zambia. The fact that in Uganda the virus was isolated from mosquitoes in an uninhabited area suggests existence of a wild reservoir, but it seems monkeys do not play this role, and birds do not play any role, so the natural reservoir remains unknown (Brès 1981).

The virus is very stable persisting for 4 months at $25^{\circ} \mathrm{C}$, but effective transmission appears to require very high densities of mosquitoes which occur only rarely.

In Egypt in October 1977 there was a large-scale livestock epizootic in the Nile Delta and the lower Nile valley as far as Aswan which spread to humans, infecting some 18,000 persons (some put it as high as 200,000) killing 598. The first record north of sub-Saharan Africa and the first record of substantial human pathogenicity. It subsided with the colder weather in mid-December but in 1978 broke out again and spread to the Sinai infecting soldiers there. The first cases of animal disease appeared to have occurred as early as July or August in southern Egypt, the subsequent epizootic causing mortality and abortion in sheep, cattle, domestic buffaloes, and camels. Another outbreak began in 1993. It is suggested its emergence in Egypt was due to the large mosquito populations produced by the Aswan dam floodlands, the virus being isolated from $C$. pipiens, the most common mosquito collected, although the isolation rate was low. Rodents, black rat, A. niloticus, Acomys c. cahirinus, and M. musculus, did not appear to play a major role in the epizootics. Sudan had epizootics in 1973 and 1976 and it is considered infection probably came from there with imported camels, $15 \%$ of which were found to have antibodies to the virus. The anopheline mosquitoes which transmitted it in Egypt, A. caballus, A. circumluteolus, and A. theileri, feed on camels, sheep, and cattle.

The disease was believed to be enzootic and endemic in Uganda.

Outbreaks of disease among cattle in the savannahs of Kenya and Tanzania between October 1997 and May 1998, and a number of deaths of people in remote areas coinciding with several months of exceptional rainfall were indicative of RVF. A high mortality was reported among the arid-country gerenuk antelope also, autopsy findings being suggestive of RVF or Bluetongue. 
An enzootic/endemic situation was found to exist in Mali, Gabon, Nigeria, Cameroun, Chad, and Angola; and it is considered possible that outbreaks in animals and man have gone undetected in these countries. The first recorded west African epizootic was in 1987 on the Senegal-Mauritania border along the Senegal river.

More than two-thirds of domestic ungulates attain lifelong immunity after infection, and immunity can be transmitted to offspring via the colostrum. Thus the risk of further epizootics is decreased as the pool of susceptibles is reduced. The complex relationship between mosquito vectors, availability of different vertebrate hosts, and their immune status, provokes instability in the occurrence of the disease (Wilson 1994). Its generally mild nature in man means it has no appreciable significance in endemic areas, only when non-immune individuals enter an endemic area can large outbreaks occur, but it poses a major threat to livestock.

\subsubsection{Family Asfarviridae}

\subsubsection{African Swine Fever ASF}

African Swine Fever ASF is a widespread viral disease indigenous to Africa and unrelated to any other known virus, being the only DNA containing arbovirus. It is well adapted to long term survival in a cycle involving arthropods and wild suids unique to Africa where it has existed for millennia (Penrith et al. 2004). Its importance is an economic one, and until domestic pigs were introduced south of the Sahara, Penrith et al. suggest by the Portuguese about 500 years ago, its cycle was entirely sylvatic, but it is now enzootic among many domestic pig populations in which it can be highly virulent. Wallace (1876) considered the true pig Sus was absent from the Aethiopian region, but Barth (1857-1858) encountered a domestic pig in the Chari basin writing, "Never in any part of Negroland, have I seen this animal in such numbers as here about the Shari". He considered it was the domestic pig of Sennar, Sus sennaarensis, but there is debate as to whether this is a true species. Nevertheless it does show that Sus has been able to survive south of the Sahara where ASF may occur, and S. sennaarensis may have reached central and eastern Africa before any Portuguese importation, coming from a non-Moslem country origin.

The main reservoir of ASF is warthog, to a lesser extent bushpig, and probably giant forest hog Hylochoerus meinertzhageni in which there is a single record. Although the disease had been seen in South Africa since 1900, it was first diagnosed in Kenya in 1910 when the presence of warthogs in the vicinity of every farm on which it had occurred was noted (Montgomery 1921). Montgomery stated simple contact was a very sure way of transmitting the infection but experimental transmission by contact between warthogs, or warthogs and domestic pigs, rarely occurs. He suggested infection might be maintained in the wild by the carnivorous habits of wild suids and that there must be some unknown reservoir, 
while a suggestion was made in 1933 that transmission might be by an intermediate host such as a winged insect. The main transmitter is now established as the eyeless argasid or soft tick Ornithodoros porcinus (=moubata) porcinus, the "eyeless tampan", found in considerable numbers in warthog burrows and sometimes infected with the virus, although how the virus is transmitted in apparently tickfree areas remains unexplained. Large amounts of the virus can apparently be inoculated by unfed first stage nymphs, implying transovarial transmission although this route of infection may not be high. Naturally infected $O$. m. porcinus fed on domestic pigs regularly transmit the disease and they presumably play an important role in disseminating the virus among warthog populations. Infected fourth or later stage nymphs were collected from a single burrow in QENP where the virus was not present in many thousands of adult ticks examined, and 1495 ticks from the same burrow were also found to be free of it. It was demonstrated the virus could multiply in the tick host and persist for at least 15 months, although in others it disappeared within four. Experimentally it has been maintained in a transmissible state for 3 years. The tick hosts appear unaffected and the relatively constant and high levels of viral maintenance suggest an ability to regulate viral replication to keep it compatible with host survival. The amount of virus, and hence quantity of blood, a tick needs to be infective has not been found in sufficient concentration in warthogs, thus either there is an alternative vertebrate host in the same habitat capable of supporting a high ASF viraemia, the period when the virus is circulating in the blood, or young warthogs from birth to 6-7 weeks may exhibit a temporary high level viraemia following first infection. Rates of infection increase slowly with each tick developmental stage but with an abrupt increase, usually six-fold, between the last nymphal and adult stages, females having markedly higher rates than males. This higher rate is thought likely due to an increasing size of blood meals and in the case of adults, transmission of the virus by the male in copulation, shown to be as high as $88 \%$ in laboratory ticks.

Evidence suggested virus multiplication might take place in the coxal sacs and/ or glands situated at the bases of the front legs which enable engorging ticks to concentrate the cellular fraction of the blood meal (Plowright et al. 1970a). Subsequently replication was observed in cells of the filtration membrane and the collecting tubules of the coxal glands, viral levels largely equalling those in reproductive tissues where multiplication takes place also (Penrith et al. 2004).

In QENP the infection rate of sampled warthogs $(n=103)$ was $22 \%$, with the majority of positives in the age range 4-12 months. No infection was found in animals less than 3 months old $(n=6)$ and it was very infrequent in mature animals, posing the probability that where animals outside of the apparently susceptible age group have been sampled with a negative result may not mean the disease is absent. But in a sample from Serengeti, $71 \%$ were positive $(n=45)$, as were four animals less than 3 months old, and about $40 \%$ of adults were also positive. Two 8-10 week old suckling warthogs from southern Kenya were positive also. The lower frequency of infection in western Uganda is unexplained (Plowright et al. 1969). 
Other species of Ornithodoros have been infected experimentally but showed higher mortality than infected $O$. p. porcinus. O. savignyi of South Africa, the sand tampan, is generally absent from areas where wild suids occur. Ixodid ticks, Auchmeromyia larvae, lice, mosquitoes, and mites, experimentally have not been shown to transmit infection; but the stable fly $S$. calcitrans was able to carry high levels of virus for 2 days.

A number of African Swine Fever-like viruses remains unnamed.

\subsection{Contact Viruses}

\subsubsection{Family Rhabdoviridae}

\subsubsection{Rabies}

Rabies is a worldwide disease known since ancient times and referred to as caused by the bite of a mad dog in a Babylonian inscription of 2300 B.C. Pliny $c$ A.D. 70 noted "even camels are liable to rabies". From the end of the 1960s it has been reported with increasing frequency in many parts of Africa, particularly exemplified by Natal which has experienced a sharp rise in cases beginning in the 1980s, and in Kenya from 1981 onwards. This increasing frequency appears caused by an increasing human population with domestic dog ownership. It is not a disease known to have caused epidemics and is relatively insignificant as a mortality factor, but it is a widespread lethal disease hosted by wild species. It is a Lyssavirus, the genus of the Family Rhabdoviridae, capable of producing fatal encephalitis in a wide variety of mammal species. The type species is distributed worldwide and is enzootic in the tropical, subtropical, and temperate regions of Africa, where it undergoes sporadic epizootic cycles. But Africa is home to six other species also: Lagos bat virus isolated from fruit bats in Nigeria, CAR, and South Africa; Mokola virus, isolated from man in Nigeria in 1968 infection of which may prove fatal, shrews Crocidura spp. in Nigeria and Cameroun, harsh-furred mouse Lophuromys sikapusi in CAR, rodents in South Africa, and cats and dogs in Zimbabwe; and may be transmissible by mosquitoes. Duvenhage virus is found in the bat Nycteris thebaica in Zimbabwe and other insectivorous bats in South Africa where a man bitten by a bat died from it; Nigerian horse virus is known to affect horses only; Obodhiang virus found in Mansonia uniformis mosquitoes in the Sudan, and Kontokan virus in Culicoides midges in Nigeria, antibodies of which have been found in domestic herbivores, wild rodents, and insectivores, causing a disease resembling bovine ephemeral fever.

A pre-existing indigenous transmission cycle for rabies is believed to predate the arrival of European dogs, although Barrow (1801-1804) considered southern Africa was free from "the canine madness" and its existence was not owing to the heat of the climate "as we are apt to suppose in England" because of its non- 
occurrence in Egypt, the West Indies, and other tropical situations, as well as the Cape of Good Hope. However Thunberg (1793-1795), travelling to Kaffraria in 1772, having crossed the Gouds River to Daniel Pinard's farm, was informed the Rabies canina and vulpina had prevailed, meaning that dogs and jackals were affected. Burchell (1822-1824) was somewhat equivocal, writing in 1812 both that it was unknown and that it was rare, "The hydrophobia or canine madness, is unknown in these regions; and indeed in the whole of the southernmost part of Africa. Even in Cape Colony this dreadful disorder is so rare, that I never heard of an instance of it during the 5 years of my being in that part of the globe". Shepstone alluded to an outbreak at Wesleyville in 1823 (Cluver 1927) and Kay (1833) noted, "It has been asserted, by a highly respectable writer on the Cape, that canine madness and hydrophobia form no part of the diseases indigenous to Southern Africa: the author, however, had here an opportunity of witnessing a most decided case of this kind in October 1827; and many others, equally direful, have taken place in different parts of the colony". He recorded also that immense swarms of dogs were met with everywhere, constituting one of the chief nuisances of the country. Livingstone wrote in 1845, "A kind of madness previously unknown to the natives appeared last year among the dogs, but it differs essentially from Hydrophobia. As a precautionary measure I have excised the bitten parts of all those who applied for assistance. The disease appeared to be communicated to a child and a calf. Both died" (Chamberlin 1940). Later he wrote, “... I learned that Maleke, a chief of the Bakwains. . . had been killed by the bite of a mad dog. My curiosity was strongly excited by this statement, as rabies is so rare in this country. I never heard of another case, and could not satisfy myself that even this was real hydrophobia" (Livingstone 1857). It seems most likely it was rabies in both instances, for Oosterzee, Wehr, and Hartley, in 1886 described symptoms of hydrophobia in a man allegedly bitten by a mad dog. But the first authenticated report in South Africa is credited to Hutcheon in 1893, traced to a dog imported from England (but probably infected locally). It was first recorded in Zimbabwe in 1902.

In South Africa two distinct variants have been isolated from 33 different carnivore species maintained by independent cycles, and from 23 herbivore species. One variant is primarily associated with the domestic dog but affects jackals also, jackal outbreaks being driven by dogs; and bat-eared foxes Otocyon megalotis killing $90 \%$ of a population of the latter in Serengeti in the late 1980s. It was isolated from a bat-eared fox first from Amboseli (Debbie 1970). In South Africa cases in bat-eared foxes were reported only sporadically from the 1950s to 1970, but then incidence increased five-fold with infection in the Western Cape now apparently maintained independently of domestic dogs (Thomson and Meredith 1993). Fluctuations in bat-eared fox populations with the sudden disappearance of families were reported by Leakey (1969) as possibly caused by “distemper". He thought it might affect hunting dogs also.

The other variant is associated with viverrids and genets. The viverrid variant which is maintained in the yellow mongoose Cynictis pencillata in South Africa as a stable enzootic infection is thought to have arisen probably recently from the canid virus, and each of these variants has crossed species barriers to infect other 
mammals with no evidence of genetic modification in the virus recovered from nonreservoir host species (Nel et al. 1997). In East Africa spillover from the strain maintained in the domestic dog occurs among many carnivore species including Ethiopian wolf $C$. simensis, wild dog, spotted hyaena, and lion. The Ethiopian wolf in the Bale Mountains was seriously affected by an epizootic in the early 1990s, reducing survival rates by $70-75 \%$ and threatening the species with extinction. In West Africa the domestic dog is regarded as the primary reservoir host, but there are few studies of wild carnivores although it has been reported from a civet cat Civettictis civetta in Nigeria (Kasali 1977).

Rinderpest in Serengeti wildebeest formerly may have provided cross-immunity against CDV in the surrounding domestic dog population. Removal of this with the disappearance of rinderpest has resulted in an increased population of domestic dogs and an increase in rabies infection, which in turn is transmitted to other species. Diagnosed in samples between 1986 and 1991, wild dogs in Serengeti were believed to have been exterminated by rabies contracted from the domestic dog source, all disappearing by 1992 and remaining absent for 10 years. Mortality peaked in 1987-1988 when it affected bat-eared foxes also.

Plehn (1897) reported in 1895 no case of rabies had been observed either on the East or the West coast, but Becker (1887) reported in 1882 at Karema in Tanzania that a White Father missionary had been bitten by a dog on his wrist which he had deeply cauterized fearing rabies, Becker noting "rabies exists here, as with us" (i.e. in Belgium). The missionary was not affected however.

The earliest confirmed record in East Africa was that of a rabid dog near Nairobi in 1912 but it had long been known apparently to the people of South Kavirondo who called the disease in dogs and jackals swao. Percival (1918) stated that every few years one heard of a jackal attacking man in a strange way or wandering unconcernedly into farms in daylight, but although he had heard of several cases of Africans and dogs being bitten he had not heard of any further development. Since 1931 it was confined to the west of the Rift Valley and Nyanza Province.

Likely candidates for maintaining a sylvatic cycle in Kenya are the silver-backed jackal C. mesomelas, honey badger Mellivora capensis, and white-tailed mongoose Ichneumia albicauda. It is considered there may be a sylvatic reservoir in Kenya's Eastern Province and in northern Kenya it may involve the jackal and other carnivores. Civet cats and hyaenas have been recorded also as dying from rabies in Kenya (Davies 1981).

A suspicious case was reported in a dog at Mpwapwa in Tanzania 1923, but it was diagnosed in dogs in the Mara region in 1932-1933 controlled by 1947, and believed to have moved south into Tanzania if not present there already, Iringa and Mbeya becoming the core of the enzootic zone in Tanzania. In 1938 it was considered rabies was enzootic in the wild carnivora, especially jackal, two cases in dogs and a suspected case in a donkey having occurred. Introductions into new areas were by infected dogs and the reported incidence among wild animals was always very low, jackals providing only $3.3 \%(n=12)$ of all positive cases in the years 1966-1970, while only five cases were reported in hyaenas in the same period and only one case in a "fox" (Rweyemamu et al. 1973). Before this, in 1960, there 
were a few human cases, invariably fatal, in the Kibondo and Ngara Districts on the borders of Rwanda and Burundi from whence infection had entered Tanzania.

In 1981 an outbreak among greater kudu in Namibia caused death of an estimated 10,000-15,000 over 3 years transmission being by salivary contamination of browse, abnormally high kudu densities being considered a major facilitating factor.

Despite record numbers of jackal cases reported in Zimbabwe in the 1990s there was no clear evidence that jackals had become maintenance hosts, and most wild animal populations appear unable to sustain epizootics initiated by spill-over infection from reservoir hosts (Cleaveland 1998).

\subsubsection{Family Reoviridae}

\subsubsection{African Horse Sickness AHS}

African horse sickness or AHS is a mild to fatal disease of equids transmitted by Culicoides midges with a mortality rate in horses of up to $95 \%$. Occurring throughout sub-Saharan Africa and in Egypt and the Middle East, it was reported in Yemen in 1327 and is believed also to have been the cause of death of horses imported into East Africa by Francisco Baro in 1569. Among wild animals antibodies have been found only in zebra, elephant, and both black and white rhinoceros. The possibility that elephants are reservoir hosts is questionable, tests in South Africa proving negative although positive results were obtained in Kenya. A continuous transmission cycle of the virus between Culicoides vectors and zebras exists in Kruger NP (Coetzer and Guthrie 2004), but there are no apparent pathogenic effects in zebras

\subsubsection{Family Picornaviridae}

\subsubsection{Encephalomyocarditis Virus EMC}

Encephalomyocarditis virus or EMC is a resistant virus of worldwide distribution affecting a wide range of domestic and wild species, also found in man, contracted usually from infected faeces and urine of rats the vast majority of cases probably being asymptomatic and going unrecognized. Rats and mice commonly carry antibodies to it but contact transmission among rodents is rare and their role as the natural host has been questioned (Alexander 2004). Normally infections are subclinical but depending upon the host and the viral strain it can be fatal. It caused the deaths of eight captive African elephants, and an irruption of rats in Kruger NP in 1993-1994 resulted in an outbreak in wild elephants, causing acute mortality from heart failure of 64 animals widely scattered in the Park. No increased mortality was observed in other animals in the Park (Grobler et al. 1995) but at the end of November 1993 an epizootic 
of EMC broke out in tree squirrels Paraxerus cepapi in the far north of the Park at a time when it was considered there may have been a population irruption of rodents, occurring also in adjoining Mozambique. Antibodies were found in black rat, Aethomys chrysophilus, M. natalensis, Saccostomus campestris, and Tatera leucogaster; but apart from the first two species not until the epizootic was advanced. In mid-1994 there were reports of a rodent plague in the Limpopo Valley to the west of Kruger NP. The rodent outbreak declined rapidly after June 1994. An analogous countrywide population explosion of rodents had last occurred in South Africa in 1968. EMC has long been known to be present in South Africa and it may have been continuously present in Kruger NP, but no similar outbreak of disease in elephants has been recorded since records began in the late 1950s. It was present in elephants in 1987, and in 1993 and $1994,53.5 \%(\mathrm{n}=116)$ and $14.5 \%(\mathrm{n}=172)$ respectively tested positive. It is not known whether contagion or indirect transmission occurs between elephants. A number of people who had been in contact with the virus tested positive for antibodies but none could recall being indisposed.

Outside of Kruger NP antibodies have been found in Mastomys coucha, Rhabdomys pumilio, Otomys irroratus, and Malacothrix typica, the virus first demonstrated in South Africa in Mastomys spp. (probably M. coucha) in 1961 and in surveys in 1968, a year when it was thought to have been particularly active, but it is not known what part rodents may play in maintaining the disease. It may be transmitted via faeces but the period of virus excretion may be limited to $24 \mathrm{~h}$, although once excreted into the environment the virus is resistant and can pollute standing water.

\subsubsection{Foot and Mouth Disease FMD}

Buffalo are host to Foot and Mouth Disease FMD, a highly contagious globally distributed viral disease with unique African strains. Dissemination from an infected animal is mainly through secretion, excretion, and expiration of the virus. It has been detected in the ambient air surrounding cattle and thus can be spread by wind. Cattle may appear to recover completely from an infection but then remain carriers for up to 2 years afterwards. Worldwide more than 20 Families have been found susceptible to infection whether naturally or experimentally, and at least 19 species of African mammal, namely: East African hedgehog, African porcupine, mole rat, field rat A. abyssinicus, tree hyrax Dendrohyrax sp., warthog, buffalo, bushbuck, kudu, eland, grey duiker, waterbuck, springbok, impala, hartebeest, wildebeest, roan and sable antelope, and gemsbok (Macaulay 1964). Thus we may suppose that all artiodactyl ungulates are probably susceptible and many other species also, but few are carriers. Birds may play a significant role in indirect transmission over long distances. An experimentally infected kudu died 7 days after infection but epizootic outbreaks have not been reported in game. In cattle it is more virulent than in buffalo but many African breeds react with mild clinical symptoms only. It was enzootic among cattle in Europe until the end of the nineteenth century so cattle migrating south in Africa probably already carried their own strains, but 
introduction to the African strain may have presented an added challenge to invading cattle populations.

Seven strains have been isolated. The European strains are classified as $\mathrm{O}, \mathrm{A}$, and C; while those in southern Africa are distinctive, classified as SAT1, 2, and 3; and there is an Asian Asia 1 strain. In Uganda in 1972 only SAT types were isolated from buffalo in QENP and the widely-separate Lake Mburo NP, whereas for many years the strains isolated from domestic stock have been $\mathrm{O}$ and $\mathrm{A}$, and sometimes $\mathrm{C}$. Prior to this the SAT strain had been found only 6 years previously in South Africa. Thus if transfer to stock takes place from buffalo it must be very rare (Hedger et al. 1973) and supports the hypothesis that cattle brought their own FMD with them. Only the SAT type is found in South Africa but is not universally present there in wild animals. SAT1 and SAT2 spread rapidly from buffalo to buffalo, but to contract it impala need close contact with buffalo within 1 month of the buffalo becoming infected. Buffalo in Natal's Umfolozi GR were found not to harbour it, and buffalo and impala captured in Kruger NP have not been found to carry neutralizing antibody, indicating lack of exposure to the virus (Gainaru et al. 1986).

Between 1982 and 1986 types O, A, SAT1, 2, and 3, were all reported in Africa, totalling 953 reported outbreaks.

Buffalo is the only free-living species demonstrated to be the maintenance host for SAT types. Most young buffalo acquire infection soon after maternally derived passive immunity wanes at between 3 and 8 months of age, but the majority of these infections is unapparent. Infection with SAT1 and 2 has been maintained in a small isolated herd of less than 100 animals for at least 24 years, indicating that carriers play a role in maintaining the virus in buffalo herds, but carriers are generally inefficient transmitters and six carrier buffalo in experimental conditions failed to transmit infection to their calves. Experimentally, infection could be passed to cattle only by keeping buffalo and cattle in close contact for 2 years. Acutely infected buffalo with high concentrations of virus failed to transmit SAT1 virus to cattle sharing feeding and watering facilities in the same enclosure but not maintaining close contact. In another experiment, buffalo acutely infected with SAT2 virus which mixed freely with cattle, quickly transmitted the infection. However, when these cattle were replaced with others, infection failed to take place. Acutely infected buffalo failed also to transmit the virus to impala under similar experimental conditions (Gainaru et al. 1986). In six of ten buffalo isolated together, SAT1, 2, and 3 were present, but 1 year later two only showed SAT3 present, and 15 months later one animal only was still positive, presence of the virus always being low (Bengis et al. 1986). None of the cattle kept with these animals showed any evidence of infection. Thus acutely infected buffalo do not invariably transmit the virus and by 4 weeks following infection at least a high proportion are no longer secreting it. In the wild therefore only buffalo in acute stages of infection with SAT type virus, which probably would mean young animals only, are likely to provide a source of infection for other species, and then only where close contact occurs. But Gainaru et al. (1986) suggest indirect transmission by oxpecker birds Buphagus spp. or arthropods remains a possibility. The common means of infection among domestic stock is through contaminated food, and earthworms have been 
found to take up the virus from contaminated soil and become infective to pigs (Fletch 1970).

An outbreak in a cattle herd in Zimbabwe in April 1991 was typed as SAT1, found also in buffalo which used the same watering place. The virus from both cattle and buffalo was found to have a close relationship determined from gene-coding and as no outbreaks had been recorded in cattle in Zimbabwe since 1989 it was concluded the disease was transmitted to cattle from buffalo (Dawe et al. 1994).

The disease was not identified in Botswana until 1948 when it was recognized also as of separate types. There were three areas of eruption in the north of the country, in the Chobe, Botletle River, and Nata areas, the common factor being the presence of buffalo. A virulent and an occult form were present, but the occult form was eradicated from the cattle population by vaccination. In the Kalahari large concentrations of game migrate in the dry season from the interior to the cattle rearing areas of southern Botswana and, until they were restricted by fences, into Namibia and South Africa. Falconer (1972) pointed out that if a reservoir of FMD infection had been maintained in game, cattle populations in these adjacent areas would have been repeatedly infected, but no outbreaks had been recorded since 1948. In 1957 an outbreak had spread to southern Botswana when cattle had been vaccinated and the game had become heavily infected, but there was no further outbreak, indicating an inability on the part of the various wild species to harbour the disease for any length of time. No virus was recovered from small samples of springbok $(\mathrm{n}=9)$, hartebeest $(\mathrm{n}=10)$, and wildebeest $(\mathrm{n}=10)$ in 1970 , and not one showed any immunity. Buffalo however disperse away from permanent water during the wet season and may play a role in dissemination of the virus.

SAT1 and SAT2 type viruses were recovered from buffalo in the Savuti area of northern Botswana during a 1968 outbreak of SAT1 type in the Chobe area. In 1969 all three types were recovered from about half of a sample of 62 buffalo, some having high antibody levels. In 1970, 20 buffalo, ten bushbuck, and ten impala, were sampled near Kasane (Chobe area); and 20 buffalo, ten impala, ten tsessebe, and ten wildebeest, from Magwee. Near Kasane half of the buffalo had virus and high antibody levels for all three virus types, the bushbuck and impala had no virus and antibody levels were minimal. From the Magwee area only two of the 20 buffalo sampled had virus, and impala, tsessebe, and wildebeest, had minimal levels of antibody only. Thus SAT2 appeared to have existed in buffalo without transferring to cattle as it had never been recorded in cattle in Botswana. In general the buffalo maintained high levels of immunity against all three types and the disease was probably being maintained in the occult form. It has been suggested that a climatic or a stress factor when buffalo moved out of the swamps could activate the disease, resulting in outbreaks when other species of wild animal might also be exposed to larger amounts of virus and contract the disease (Falconer 1972).

FMD may be present in a wild population without showing overt signs, in the carrier state or in the pharynx of infected animals, or occurring as mild lesions from time to time in animals with waning immunity, and as new strains arise the disease may spread to other animals of the same species. 


\subsection{Protozoan Diseases}

\subsubsection{Sarcocystis}

For long considered a mystery, sarcocystis was eventually identified as a coccidial protozoan. Worldwide in occurrence it is found as small sacs filled with spores in the muscles which in domestic stock characteristically causes a chronic subclinical infection in the cardiac and/or skeletal muscles and can give rise to encephalitis, abortion, or premature birth. It requires two hosts, the definitive host in which a sexual cycle takes place being a carnivore or omnivore which consumes the spores. This might be avian such as a vulture, but it is common in lions in South Africa. When the sarcocysts are ingested bradyzoites liberated by digestion in the stomach penetrate the mucosa of the small intestine and transform into male (micro) and female (macro) gametocytes within hours and conjugate forming an oocyst, which then sporulates. Both sporulating and fully sporulated oocysts have been found in the skeletal muscle of baboons in South Africa which are frequently both intermediate and definitive hosts (Markus 1978). The intermediate host becomes infected by ingesting the sporocysts releasing sporozoites in the small intestine, their further development unknown until they appear in the mesenteric arteries and lymph nodes where they eventually liberate merozoites into the blood initiating development of the sarcocysts in muscle, bradyzoites being formed, the infective stage for the consumer (Markus et al. 2004). First described from Korin gazelle Gazella rufifrons in the Sudan as Sarcocystis gazellae in 1913, it was followed by S. bubalis in Coke's hartebeest, $S$. woodhousei in Grant's gazelle, and unnamed species in grey duiker, reedbuck, Uganda kob, Thomson's gazelle, topi, and wildebeest. Mandour and Keymer (1970) described it in bushbuck, greater kudu, puku, common water buck, defassa waterbuck, and Grant's gazelle. That in defassa waterbuck was described as a new species S. nelsoni. Sarcocystis sp. have been found also in buffalo in CAR.

\subsubsection{Family Theileridae - Theilerioses}

\subsubsection{East Coast Fever ECF}

ECF, or theileriosis, the Texas fever of America, is a protozoal infection caused by Theileria parva parva which invades the lymphocytes, vector borne by hard ticks. In 1977 it was estimated 500,000 cattle died each year in East Africa alone despite attempts at tick control and prophylactic measures, annual calf losses being 13-20\%. Although known in East Africa for a long time and may have originated there, it was recognized as a problem in southern Africa in 1904 only when it was imported with cattle from Dar es Salaam and spread wherever suitable tick hosts existed. Barnett and Brocklesby (1968) suggested T. parva was originally acquired 
from cattle as the buffalo and vector ticks existed in Central and South Africa together with cattle before 1904 without recognizable theileriasis in either cattle or buffalo. When introduced with cattle from East Africa it behaved like a disease that was new to the area. Koch (1898) found that cattle brought to the coast at Dar es Salaam fell ill indicating it was enzootic in the coastal area, and using ticks collected from sick cattle infected cattle at Kwai in the Usambaras, where the disease was unknown, with a mild viraemia (except for one already weak animal which died). Many of the ticks died in transit and Koch suggested the parasite may have lost its virulence. But Churchill (1908) claimed the disease came across the border into Kenya in 1905, thus the enzootic area does not seem to have extended northwards along the coast at that date. Theiler (1910) described its distribution as follows: ". . .certain places on the coast, then along the border of British East Africa around the Kilimandjoro, south of the Victoria Nyanza, in Huanza [Mwanza], and as far inland as Ruanda and Urundi behind the Victoria Nyanza, between this lake and Tanganyika, bordering the Kiwuland and the Belgian Congo;.... on the northern border of the Nyassa, in the districts of Langenburg, and on several places south of the British East Africa border, and inland (Mangati)".

Today it is known that the principal vector, the tick $R$. appendiculatus, is well established in some of these areas. T. p. parva is a subspecific variant of T. parva, the other being T. p. lawrencei of Corridor Disease of the African buffalo in which it causes few if any symptoms but is usually fatal to cattle. T. p. lawrence i is more antigenically variable than $T$. p. parva which suggests it may be derived from the former which if passaged through cattle becomes indistinguishable from the latter. Naïve herds can experience up to $90 \%$ mortality with survivors achieving a degree of tolerance but at the cost of growth and productivity. Zebu cattle display a higher tolerance than other breeds. T. mutans, of which the vectors are several species of Amblyomma tick, is more widespread than T. parva but considered non-pathogenic, although severe anaemia in cattle as a result of infection has been described in Kenya and has been associated with the presence of buffalo.

The actual incidence of buffalo-derived theileriosis is not known. The infection rate in cattle is affected by the total parasite load and their antigenic reaction. Indigenous African cattle appear to have evolved higher levels of tick resistance carrying less ticks than European breeds on the same pasture. They have a greater tolerance of T. p. parva infection also. Many wild animals host Theileria spp. and Grootenhuis (1979) considered there was not an eland in Kenya which did not carry theilerial piroplasms. But the main established link is between buffalo and cattle. As the eland piroplasms are T. mutans eland do not seem to be involved in transmission of ECF. Of those named, species have been assigned to bushbuck T. tragelaphi, kudu T. strepsicerosi, grey duiker T. sylvicaprae, Grant's gazelle $T$. stordyi, wildebeest $T$. gorgonis, and roan antelope $T$. hippotragi. Carmichael and Hobday (1975) found the theilerial piroplasms which cause ECF in all species they examined in northern Botswana but predominantly in buffalo (16.3\%). One impala appeared pathologically affected and one kudu had a high level of parasitaemia. Theileria have been found in a number of antelopes elsewhere, but the incidence in buffalo was much lower than that recorded in buffalo in western Uganda (88\%) or 
in South Africa's Kruger NP (97\%). Buffalo can harbour T. lawrencei, T. mutans, and T. parva, together, although some consider T. lawrencei and T. parva may be synonymous but strains may vary in virulence. Infected kudu, eland, and giraffe, have shown anaemia with heavy infections of theileria.

No species were found infected with the theileria Haematoxenus but it has been described from impala in Tanzania and buffalo in CAR ( $H$. veliferus) and Uganda. It was not found in large numbers of buffalo from other areas in East Africa, suggesting a restricted distribution. A theileria isolated from eland in Kenya and named Cytauxoon taurotragi (Martin and Brocklesby 1960) is now classified as T. taurotragi, one of the benign parasites of cattle known collectively as T. mutans, transmitted by $R$. appendiculatus. Grootenhuis (1979) considered theileriosis in cattle was caused by the several species of Theileria acting either individually or in concert.

\subsubsection{Family Babesiidae - Babesioses}

Babesia spp., 'redwater' of cattle, are piroplasms transmitted by ticks of the genera Boophilus, Rhipicephalus and Hyalomma. Five species have been found in primates, including Babesia perodictici in the potto Perodicticus potto and B. galagolata in the galago Galago crassicaudatus. The latter has a very wide host range and is possibly one of the least host-specific babesias known. $B$. equi is common in zebras from northern Kenya to northern Tanzania with probably $100 \%$ of populations infected. It has caused the death of captured Grevy's zebra in which high levels of parasitization have been found. B. canis has been found in side-striped jackal $C$. adustus in Kenya (Dennig 1964) and B.felis in lions in both Kenya and Uganda. No babesias were found in buffalo but one wildebeest and one tsessebe were infected in Carmichael and Hobday's (1975) study in northern Botswana.

Another piroplasm, Echinozoon hoogstraali, is unique to the rock hyrax Heterohyrax syriacus in Sudan, in which $50 \%(\mathrm{n}=12)$ of a sample was found infected.

Nuttalia loxodontis, a piroplasm of elephants isolated in DR Congo, may be transmitted by the elephant ticks Ambylomma tholloni and/or Dermacentor circumguttatus. Its effects on elephant are unknown.

\subsection{Mycotic Diseases}

Austwick (1968) pointed out that mycotic diseases, most of which exist saprophytically in soil and in plant debris, are perhaps the most neglected diseases of wild life. Dermatophilus congolensis, which causes one of the commonest skin infections in domestic animals, identified first in DR Congo in 1915 and found since to occur almost world-wide, was slowly being recognized in wild life. It has been 
reported in zebra, giraffe, and Thomson's gazelle, but there is no evidence that it causes the fatal streptotrichosis seen in domestic stock. A major epizootic of Mycoplasma pneumonia, mycoplasmas being organisms between bacteria and viruses, caused death of an estimated $23 \%$ of the elephant population in Lake Manyara NP in 1977 following severe drought in 1976, compared with an annual mortality between 1966 and 1981 of $3 \%$.

\subsection{Notes}

1. Prions are proteinaceous infectious particles which are neither viruses nor viroids but normal proteins which after modification are associated with spongiform encephalopathic diseases like Creutzfeldt-Jakob disease in humans and bovine spongiform encephalitis in ungulates, unique to each species.

Viroids are small RNA molecules of unique structure that can replicate and cause disease primarily in plants.

2. Equorum illic ingens pretium est, nec facillime ibi aluntur, ob aridam tellurem, nam torrida est plaga, quæ pabula non producit, facitque æstus nimius, ut equorum inguina intumescant, ut vix meiere possint.

The price of the horses there is great, and not most easily (there) maintained, on account of the dry land, for the region is parched, which produces no fodder, and makes excessive heat, so that the horses' groins begin to swell, so that they can (only) make water with difficulty. 